\title{
Mathematically Modelling the Dynamics of Cholesterol Metabolism and Ageing
}

\author{
A. E. Morgan ${ }^{a}$, K. M. Mooney ${ }^{b}$, S. J. Wilkinson ${ }^{a}$, N. A. Pickles ${ }^{c}$, and M. T. Mc Auley ${ }^{a}$ \\ a Department of Chemical Engineering, University of Chester, Thornton Science Park, Chester, \\ $\mathrm{CH} 24 \mathrm{NU}$
}

${ }^{b}$ Faculty of Health and Social Care, Edge Hill University, Ormskirk, Lancashire, L39 4QP
${ }^{c}$ Department of Biological Sciences, University of Chester, Parkgate Road, Chester, CH1 4BJ

Keywords

Cholesterol, ageing, low density lipoprotein cholesterol (LDL-C), high density lipoprotein cholesterol (HDL-C), cholesterol ester transfer protein (CETP)

\begin{abstract}
Cardiovascular disease (CVD) is the leading cause of morbidity and mortality in the UK. This condition becomes increasingly prevalent during ageing; $34.1 \%$ and $29.8 \%$ of males and females respectively, over 75 years of age have an underlying cardiovascular problem. The dysregulation of cholesterol metabolism is inextricably correlated with cardiovascular health and for this reason low density lipoprotein cholesterol (LDL-C) and high density lipoprotein cholesterol (HDL-C) are routinely used as biomarkers of cardiovascular disease (CVD) risk. The aim of this work was to use mathematical modelling to explore how cholesterol metabolism is affected by the ageing process. To do this we updated a previously published whole-body mathematical model of cholesterol metabolism to include an additional 96 mechanisms that are fundamental to this biological system. Additional mechanisms were added to cholesterol absorption, cholesterol synthesis, reverse cholesterol transport (RCT), bile acid synthesis, and their enterohepatic circulation. The sensitivity of the model was explored by the use of both local and global parameter scans. In addition, acute cholesterol feeding was used to explore the effectiveness of the regulatory mechanisms which are responsible for maintaining whole-body cholesterol balance. It was found that our model behaves as a hypo-responder to cholesterol feeding, while both the hepatic and intestinal pools of cholesterol increased significantly. The model was also used to explore the effects of ageing in tandem with three different CETP genotypes. Ageing in the presence of an atheroprotective CETP genotype, conferring low CETP activity, resulted in a $0.6 \%$ increase in LDL-C. In comparison, ageing with a genotype reflective of high CETP activity, resulted in a $1.6 \%$ increase in LDL-C. Thus, the model has illustrated the importance of the I405V CETP genotype and its potential role in healthy ageing.
\end{abstract}




\subsection{Introduction}

Life expectancy is increasing at a phenomenal rate. If one examines life expectancy in the UK at the beginning of the 1980 s and compares it to the projected value for 2081 , then this demographic shift in favour of older people is truly emphasized. Males and females born in 1981, had a life expectancy of 70.9 and 76.9 years respectively, while the projected values for 2081 are 89.7 and 92.5 years (OFNS, 2013). It is also anticipated that the percentage of individuals in the UK over 60 years will double to $22 \%$ by 2050, when compared to 2000 (WHO, 2014). Moreover by 2050 it is anticipated, that the number of individuals $>80$ years will quadruple (WHO, 2014). This increase in life expectancy comes with significant challenges for older people. Most significant of these is maintaining health status by remaining disease free. Of the diseases which burden older people in the UK, CVD is the leading cause of morbidity $(30.3 \%)$ in individuals $\geq 60$ years of age (Prince et al., 2015). CVD has many risk factors (Appelman et al., 2015), however the plasma levels of total cholesterol, LDL-C and HDL-C are long established gold standard risk factors for CVD (Appelman et al., 2015). Specifically, rises in both total and LDL-C result in an increase in CVD risk, while conversely a rise in HDL-C results in a decrease in CVD risk (Austin et al., 1988; Cooney et al., 2009). On a population basis, ageing has been shown to result in a rise in both total and LDL-C in males and females (Abbott et al., 1983). For example, data from the Framingham Study demonstrates there is a gradual rise in LDL-C from an initial value of $\sim 100 \mathrm{mg} / \mathrm{dL}$ in 15-19 year olds (males and females), to 143 and $159 \mathrm{mg} / \mathrm{dL}$ in 60-64 year olds, males and females respectively. Beyond the 6th decade, LDL-C levels continue to rise in females, however they marginally decline in males within this population (Abbott et al., 1983). The most likely reason for this is that ageing results in the dysregulation of whole-body cholesterol metabolism (Mooney and Mc Auley, 2015). Whole-body cholesterol metabolism is regulated by a number of factors including cholesterol synthesis, intestinal cholesterol absorption, hepatic cholesterol uptake (known as reverse cholesterol transport), cholesterol excretion, bile acid production, and deconjugation by intestinal microflora and subsequent excretion. Changes to any of these mechanisms can dysregulate cholesterol metabolism (Morgan et al., 2016).

The multifaceted nature of cholesterol metabolism, the complexities of its dynamics, and the long term impact of the ageing process on its behaviour makes studying this system a challenge (Mc Auley and Mooney, 2014). In recent years however, several groups have adopted a systems level approach to investigating lipid metabolism (Mc Auley and Mooney, 2015; Mooney et al., 2016). The majority of these models have centred on specific metabolic processes, including those directed at lipoprotein metabolism (Hubner et al., 2008; Shorten and Upreti, 2005; Sips et al., 2014), cholesterol biosynthesis (Bhattacharya et al., 2014; Kervizic and Corcos, 2008; Mazein et al., 2013; Watterson et al., 2013), reverse cholesterol transport (Lu et al., 2014), adipocyte metabolism (Micheloni et al., 2015), hepatocyte metabolism (Jerby et al., 2010), cholesterol regulatory enzymes (Chapman et al., 2010), whole-body plasma cholesterol metabolism (van de Pas et al., 2012) and enterohepatic circulation of bile acids (Mishra et al., 2014). These models all have noteworthy features and have added to our understanding of lipid metabolism. Among the computational systems biology models, the model by Mc Auley et al (2012) provides an integrated template for investigating ageing and whole-body cholesterol metabolism (Mc Auley et al., 2012). This model is encoded in the systems biology markup language (SBML) (Hucka et al., 2004; Hucka et al., 2003), and is part of the curated section in the BioModels web site; a repository for models encased in SBML exchange framework (Le Novère et al., 2006; Li et al., 2010). This makes the model straightforward to adapt and update. The adaptable nature of this model was emphasized recently by Mishra, Somvanshi \& Venkatesh (2014), who used this model in tandem with another model (Demirezen and Barlas, 2008). Their combined model included the variables body weight, diet and exercise and they analysed the feedback mechanisms of enterohepatic circulation of bile acids; specifically, bile acid synthesis, interactions with dietary lipids, and excretion. Despite its integrated nature and its focus on ageing, the model by Mc Auley et al. (2012) is lacking several key mechanisms that are fundamental to cholesterol metabolism. These key mechanisms include plasma membrane receptors, nuclear receptors and a variety of in vivo and intestinal microfloral enzymes. It is imperative that these factors are included in any holistic representation of cholesterol metabolism. Thus, the aims of this work were fourfold. 1) To mechanistically update the wholebody mathematical model of cholesterol metabolism by Mc Auley et al. (2012). 2) To use the 
updated model to explore the role of cholesterol and saturated fat (SFA) feeding on lipoprotein profile. 3) To examine the role of age-related alterations to cholesterol metabolism on the lipoprotein profile, specifically, cholesterol absorption, LDL-C clearance, and bile acid synthesis and subsequent deconjugation. 4) To test the model using pharmacological interventions that have been used in vivo to treat hypercholesterolaemia.

\subsection{Overview of Cholesterol Metabolism}

Maintaining cholesterol metabolism is a subtle balancing act between the amount of cholesterol ingested, absorbed, excreted and synthesised (Mc Auley et al., 2005). Ingested cholesterol, exists as esters, and free cholesterol (lqbal and Hussain, 2009). Esterified cholesterol is hydrolysed to free cholesterol by cholesterol ester hydrolase (CEH)/cholesterol esterase/bile salt-dependent lipase (BSDL) for micelle incorporation (Ikeda et al., 2002). This facilitates the absorption into the jejunocyte by Neimann-Pick C1-Like 1 protein (NPC1L1) endocytosis (Jia et al., 2011; Petersen et al., 2008). Internalized free cholesterol is converted to esterified cholesterol by acyl coenzyme A: cholesterol acyltransferase 2 (ACAT2). It is then transported to apolipoprotein (apo) B-48 to form part of a nascent chylomicron via microsomal triglyceride transfer protein (MTP) (Atzel and Wetterau, 1993; Atzel and Wetterau, 1994). Acquisition of apo $\mathrm{C}-\mathrm{II}$ and $\mathrm{E}$ converts the chylomicron to a mature chylomicron. On delivery to adipose/muscle tissue, apo C-II activates of lipoprotein lipase (LPL), which hydrolysis TAG releasing glycerol and FFAs (Kersten, 2014; Olivecrona and Beisiegel, 1997). Hepatocytes then uptake the chylomicron remnants via LDLr and low density lipoprotein receptor-related protein (LRP), for degradation (Cooper, 1997). Reverse cholesterol transport (RCT) removes excess cholesterol from peripheral tissues and transports it to the liver for excretion in bile or conversion to bile acids (Ohashi et al., 2005; Scheibner et al., 1994). RCT begins with the efflux of cholesterol to nascent HDLs (ndHDL) (Lund-Katz et al., 2013). Cholesterol efflux can occur via the receptors ABC-A1 (He et al., 2015) or scavenger receptor class B type 1 (SR-B1) (Ji et al., 2011), or via passive diffusion (Gillotte et al., 1998). Lecithin-cholesterol acyltransferase (LCAT) esterifies the incorporated cholesterol, converting the ndHDL to $\mathrm{HDL}_{3}$ (Sorci-Thomas et al., 1990). The assembly of 2 small, dense, $\mathrm{HDL}_{3}$ molecules, in the presence of phospholipid transfer protein (PLTP), induces the formation of a larger $\mathrm{HDL}_{2}$ molecule (Chirackal Manavalan et al., 2014), which can be reversed by hepatic lipase (HL) (Patsch et al., 1987). Cholesterol esters can enter the liver directly via the receptor SR-B1, or via CETP, which facilitates the 1:1 exchange of cholesterol esters from HDL2 with TAGs from very low density lipoprotein (VLDL) and LDL (Zhang et al., 2015). These lipoproteins return the esterified cholesterol to the liver (Brown and Goldstein, 1984). LDL can also return cholesterol esters to peripheral tissues (Baigent et al., 2010). VLDLs and IDLs that haven't deposited cholesterol esters into the liver, can be metabolised via LPL and hormone sensitive lipase (HSL) to LDL.

The enterohepatic circulation of bile acids occurs between 4-12 times per day, but only $5 \%$ per day are lost in faeces (Gerard, 2013), and of this, $98 \%$ is in the unconjugated form (Batta et al., 1999). Although preferentially hydrolysing glyco-conjugated bile acids, both glyco- and tauroconjugated bile acids can be converted to unconjugated bile acids whilst in the intestinal lumen by the hydrolysis of the amine bond, and removal of glycine or taurine by bacterial bile salt hydrolase (BSH) (Jarocki et al., 2014). Certain intestinal microflora have the ability to produce $\mathrm{BSH}$, but Lactobacillus species are responsible for $86 \%$ of the BSH activity in the ileum, and $74 \%$ in the caecum (Tannock et al., 1989). The probiotic administration of BSH-producing strains can lead to a decrease of $63.2 \%$ in plasma LDL-C levels. This is due to the increase in excreted bile acids, leading to enhanced de novo synthesis of bile acids from cholesterol, to replace those excreted. Furthermore, there is a decrease in cholesterol solubility due to an increase in the proportion of unconjugated bile acids. In addition, there is a rise in the ratio of propionate to acetate (Begley et al., 2006; Guo and Li, 2013). However, this treatment strategy is controversial as evidence suggests that the byproducts of unconjugated bile acids have been associated with the dysregulation of mucosal functioning (Ajouz et al., 2014; Baptissart et al., 2013). 


\subsection{How Cholesterol Metabolism changes with Age}

It has been consistently shown that LDL-C increases with age in both males and females across different population groups (Abbott et al., 1983; Yang et al., 2012). A number of mechanisms have been implicated in this age-related rise in LDL-C. For example, it has been suggested that an increase in the absorption of dietary cholesterol is one of the factors responsible for the increase of serum LDL-C with age (Duan et al., 2006; Hollander and Morgan, 1979). Murine models demonstrate that this increase in cholesterol absorption is correlated with the agerelated increase in the apical membrane receptor NPC1L1 in the duodenum and jejunum (Duan et al., 2006; Hollander and Morgan, 1979). Ageing resulted in a 17\% increase in cholesterol absorption in one murine model due to a significant increase in NPC1L1 mRNA in both the duodenum and jejunum (Duan et al., 2006). The receptor NPC1L1 plays a vital role in the absorption of dietary cholesterol. Thus, inhibiting NPC1L1 with ezetimibe is one strategy that has been adopted in the treatment of hypercholesterolaemia (Dujovne et al., 2002). Another mechanism that has been associated with the dysregulation of cholesterol metabolism is a decrease in LDLr numbers and/or activity. LDLr is responsible for the uptake of circulating LDL$C$ from the plasma. LDLr therefore lowers the plasma LDL-C levels and reduces CVD risk (Brown and Goldstein, 1984). The age-related decline in LDLr, results in a reduction in LDL clearance, thus raising the plasma LDL-C levels (Millar et al., 1995). This decline in LDLr with age could be due to the age-related increase in proprotein convertase subtilisin kexin-9 (PCSK9), a serine protease associated with LDLr degradation (Cui et al., 2010). Additionally, this could be due to the decreased demand for cholesterol for the de novo synthesis of bile acid, due to the age-related decrease in bile acid synthesis (Ericsson et al., 1991). A decline in bile acid synthesis and hepatic expression of CYP7A1 have been shown to be correlated with ageing in human subjects (Bertolotti et al., 2007). This decreases cholesterol utilisation for the de novo synthesis of bile acids (Bertolotti et al., 2007). This is supported by Bertolotti et al. (1993) who carried out a linear regression analysis which estimated that the amount of cholesterol undergoing the CYP7A1 regulated reaction in humans decreases by $60 \mathrm{mg}$ per day, every 10 years (Bertolotti et al., 1993). It is also possible that the down regulation of CYP7Al is due to the age related decline of growth hormone (GH), as illustrated by rodent studies (Parini et al., 1999). Similar studies have also illustrated that sex hormones play a role in the decline of CYP7AI, as gender differences are often observed. For example, aged female rodents often have an increased concentration of serum bile acids, whereas levels remain constant in males with age (Fu et al., 2012). This is in addition to alterations to the composition of bile acids (Trautwein et al., 1999). Gut microflora are also affected by the ageing process. Levels and species diversity of Lactobacillus and Bifidobacterium species are consistently lower in older people than younger human adults (Hopkins and Macfarlane, 2002; Hopkins et al., 2001). These species are well documented for their ability to produce the enzyme $\mathrm{BSH}$, which is responsible for the deconjugation of bile acids in the small intestine (Tanaka et al., 1999). This decrease in BSHpositive species leads to a decrease in bile acid excretion and thus a decrease in cholesterol utilisation for the de novo synthesis of replacement bile acids (Uchida et al., 1996). This could be one cause of the increase in LDL-C with age. Interestingly, supplementation with probiotic strains in elderly rodent populations has been shown to reduce LDL-C levels (Al-Sheraji et al., 2012) as well as improve gut health (Tuohy et al., 2003) and increase immunity in human subjects (Moro-Garcia et al., 2013). Mutations in the gene coding for CETP have also been linked to healthy ageing. CETP mediates the transport of cholesterol esters from HDL to LDL and VLDL. Mutation to the CETP gene has been associated with longevity in Ashkenazi Jews (Atzmon et al., 2005; Barzilai et al., 2003). The amino acid substitution of 405 isoleucine to valine (1405V) in the CETP gene results in a lower serum CETP concentration and subsequently significantly larger LDL and HDL. The CETP 1405V genotype is associated with a reduced prevalence of CVD, diabetes mellitus, and hypertension, possibly contributing to the exceptional longevity observed in these individuals (Atzmon et al., 2005; Barzilai et al., 2003). The assertion that reduced CETP levels convey a protective phenotype for healthy ageing, has led to investigations into the use of CETP inhibitors as a therapeutic strategy for the treatment of hypercholesterolaemia. For example, it has been recently revealed that in phase II clinical trials the CETP inhibitor TA-8995 decreased LDL-C by $27.4 \%$ with a $1 \mathrm{mg}$ daily dose, with minimal adverse effects (Hovingh et al., 2015). Therefore, with our updated model, there was a clear emphasis on these aspects of lipid metabolism. 


\subsection{Methods}

\subsection{Diagrammatic Representations of Whole-Body Cholesterol Metabolism}

Our updated model consists of 8 compartments which are: 1) dietary intake, 2) intestinal lumen, 3) jejunocytes, 4) ileocytes, 5) hepatic tissue, 6) blood, 7) peripheral tissue and 8) excreted (Figure 1). Figures $1-3$, were created using systems biology graphical notation (SBGN). SBGN is a graphical representation modelling format designed to be employed as a universal framework for the construction of diagrammatic representations of biological or other processes, to allow easy recognition of each species and process (Le Novere et al., 2009). Figure 1 is an adaptation of the previous SBGN diagram generated by Mc Auley et al. (2012). The SBGN diagrams were developed with VANTED (Version 2.2.1, http://vanted.ipk-gatersleben.de/, http://www.sbgn.org/Main Page) (Rohn et al., 2012). To incorporate the additional information into the SBGN diagram, the compartment previously referred to as 'intestine' was divided into 3 sub-compartments, 'intestinal lumen', 'jejunocytes' and 'ileocytes'. The role of several key processes, receptors and enzymes could then be incorporated. These include the differentiation of dietary free and esterified cholesterol, bile acid micelle formation for the uptake of free cholesterol via the NPC1L1 receptor, cholesterol esterification in the jejunum, chylomicron transport, and bile acid reabsorption. The mechanisms underpinning RCT were expanded from those represented in the original model. The enzymes PLPT, HL, LCAT and CETP and their roles in HDL subtype composition and cholesterol transport were included. Following this, additional receptors were incorporated into the peripheral tissue, hepatic tissue, and the newly formed ileocytes compartments to further elucidate the transport mechanisms of cholesterol, lipoproteins and bile acids. Next, cholesterol biosynthesis was converted from a 1 step process in the Mc Auley et al. (2012) model to an 18 step process. Overall, cholesterol biosynthesis has significantly more steps than this. However, the rationale for abstracting to an 18 step reaction system is as follows. The first 13 steps of cholesterol biosynthesis are well characterised (Liscum, 2008). The latter reactions in this process remain poorly characterised. Therefore, the reactions that were included are those that are central to the pathway and are well delineated. Due to the size and complexity of this reaction network, a separate SBGN diagram was developed to illustrate this component of the model (Figure 2). In our overall diagrammatic representation of the model (Figure 1) these reactions are simplified to 3 source and sink glyphs labelled *a, in the jejunocytes, hepatic and peripheral tissue compartments. Finally, the de novo synthesis of bile acids from hepatic cholesterol was converted from a 1 step process to a 15 step process, and similar to the cholesterol synthesis pathway, was too detailed to be represented fully in Figure 1. Bile acid synthesis is therefore represented by the source and sink glyph labelled *b in Figure 1, and is fully illustrated in Figure 3. The reactions outlined in Figure 3 are derived from various sources. In essence they are a summary of the processes that are well characterised. Some well characterised steps are excluded from the summary to reduce the process diagram size, and for clarity. For example, following the chain shortening of 4cholesten-7 $\alpha, 12 \alpha$ - diol-3-one by CYP27Al further modification by SLC27A5 (EC 6.2.1.7), ACOX2 (EC 1.17.99.3), HSD1724 (EC 1.1.135) and SCP2 (EC 2.3.1.176), occurs before cholic acid formation. There is ambiguity surrounding the re-entry of compounds involved in the alternative pathways to the final steps before the formation of cholic or deoxycholic acid resulted in gaps of knowledge. For this reason, there are process glyphs that represent a series of uncertain steps. 


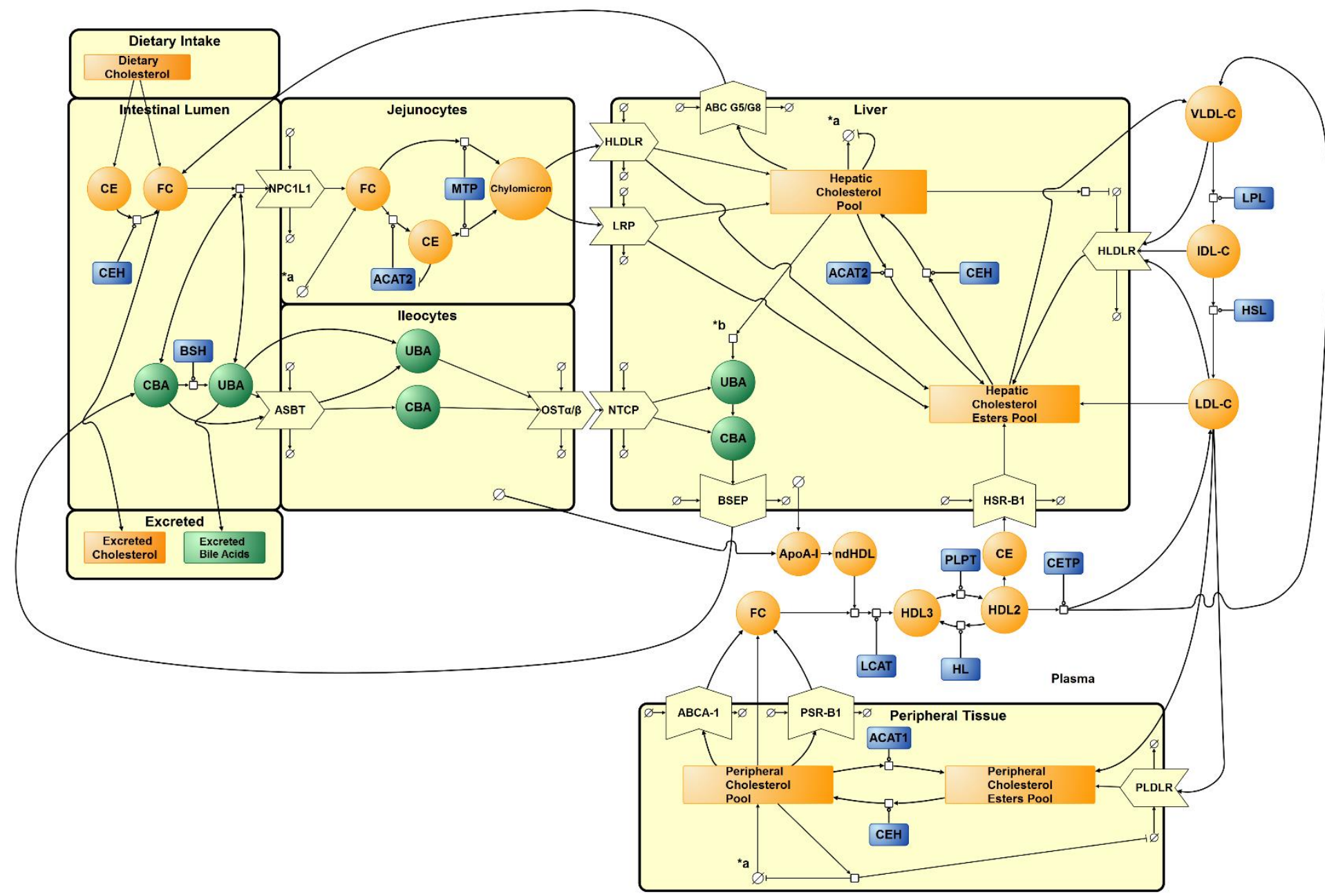

Figure 1. SBGN diagram of mathematical model of whole-body cholesterol metabolism. The diagram details the transport of cholesterol, bile acids and lipoproteins through cholesterol absorption, lipoprotein metabolism, RCT and enterohepatic circulation. For abbreviations see Table A.2. Round arrow head represent the target of a catalytic enzyme, represented as blue rounded rectangles. Arrows represent flux. Hatched process nodes represent omitted processes. T shaped arrows represent inhibition. The Greek symbol theta represents synthesis/degradation. $a^{*}$ cholesterol synthesis (see Figure 2 ), $b^{*}$ bile acid synthesis (see Figure 3). 


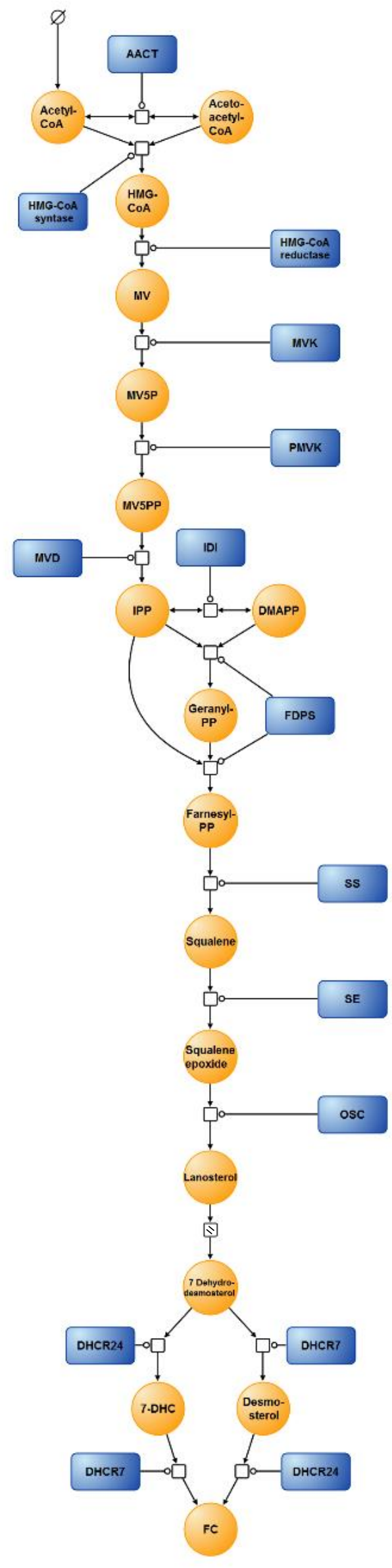

Figure 2. Cholesterol biosynthesis. Synthesis of cholesterol from acetyl CoA via intermediates HMG CoA, mevalonate, squalene and lanosterol. See Table A.2 for abbreviations. Round arrow heads represent the target of a catalytic enzyme, represented as blue rounded rectangles. Arrows represent flux. Hatched process nodes represent omitted processes. The Greek symbol theta represents synthesis. Acetoacetyl CoA thiolase catalyses the interconversion of acetyl CoA and acetoacetyl CoA. Acetyl CoA and acetoacetyl CoA undergo a condensation reaction to form 3-hydroxy-3methylglutaryl-coenzyme A (HMG CoA). HMG CoA is then converted by HMG CoA reductase to mevalonate. Phosphorylation of mevalonate forms mevalonate-5P, which is further phosphorylated to mevalonate-5PP. Decarboxylation and dehydration of mevalonate-5PP forms isopentenyl-PP (IPP), which converts to its isoform dimethylallyl-PP (DMAPP). DMAPP reacts with IPP to create geranyl-PP. Further condensation and the addition of another IPP creates farnesyl-PP. Condensation of 2 farnesyl-PP molecules forms squalene, which is converted to squalene epoxide before undergoing cyclisation to form lanosterol. A series of reactions, including the branching of 7-dehydrodesmosterol to either desmosterol or 7dehydrocholesterol, both of which can then be converted to cholesterol. 


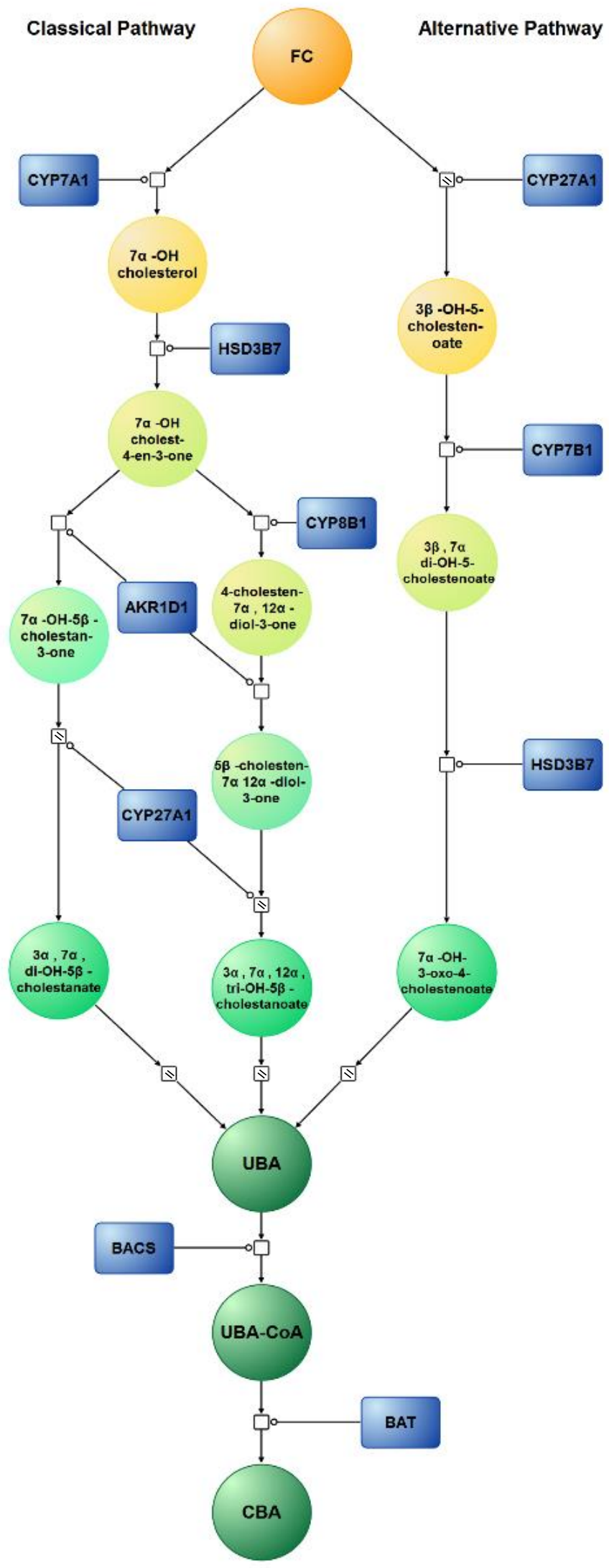

Figure 3. Bile Acid Synthesis.

Classical Pathway: Hydroxylation of cholesterol creates

$7 \alpha-$ hydroxycholesterol. Subsequent modification of the sterol ring forms $7 \alpha$-hydroxy- $5 \beta$-cholesten-3-one before the classical pathway splits, to enable the formation of either cholic acid (CA) or chenodeoxycholic acid (CDCA). For the formation of cholic acid, modification of the sterol ring by 12a-hydroxylase (CYP7B1) must occur before further modification. The side chain of $5 \beta$-cholesten- $7 \alpha$, $12 \alpha$ - diol-3-one is then acted upon by a series of oxidation steps leading to its shortening. Further modification by several enzymes then takes place to form CA. The same steps, although in the absence of CYP8B1, are undergone in the other route of the classical pathway, to form CDCA. Alternative Pathway: Side chain shortening occurs first in the alternative pathway creating $27 \alpha-$ hydroxycholesterol, before hydroxylation creates $3 \beta-7 \alpha-$ dihydroxy-5-cholestenoate. HSD3B7, CYP8B1 and AKR1D1 modification of the sterol ring can then occur, and upon further alteration, CA and CDCA can then be formed. This is followed by conjugation of $98 \%$ of these bile acids. They are they effluxed from the hepatocyte primarily by bile salt export pump (BSEP) in the rate limiting step of bile acid circulation. See Table A.2 for abbreviations. Round arrow head represent the target of catalytic enzyme, represented as blue rounded rectangles. Arrows represent flux. Hatched process nodes represent omitted processes. 


\subsection{Model Assembly and Parameterisation}

The SBML for the original model was downloaded from the BioModels database(Juty et al., 2015) (https://www.ebi.ac.uk/biomodels-main/, BIOMD0000000434). It was then imported into Version 4.14.89 of Copasi (Hoops et al., 2006). Within Copasi the model was then reassembled. The original model contained 48 species. The updated version now contains 144 species including the 4 species used as counters for the event reactions (Table A.3). The first processes to be added were the ingestion of free cholesterol and cholesterol esters. To represent these reactions we defined a number of new species, and parameters and then introduced two SBML events for each species. An event in SBML is a reaction which is activated at a particular point in time and which causes a change in the value of a species concentration, compartment size, or parameter. In this case, the rationale for including events was to represent the ingestion of cholesterol every 8 hours. This was more biologically realistic than the single reaction which represented this process previously. The events were defined in using the syntax outlined in Table A.1. Events stimulated the intake of both free cholesterol and cholesterol esters. The creation of the events reflected the intake of a meal every 8 hours. Following the assembly of the events, the entry of dietary esterified cholesterol into the intestinal lumen 3 times a day was deterministically simulated (Figure 4A). Once in the intestinal lumen, esterified cholesterol is converted to free cholesterol for entry into the jejunocytes. Figure 4B illustrates how the level of free cholesterol in the jejunocyte was affected by the entry of this converted free cholesterol. This is in addition to the $88.667 \mathrm{mg}$ of free cholesterol that is also ingested 3 times a day, and the $1000 \mathrm{mg} /$ day of biliary cholesterol effluxed back into the lumen from the liver. Within the model, free cholesterol contained in the jejunum fluctuated. Initial steady state values for free and esterified cholesterol in the hepatic or peripheral tissues were calculated based on the experimental data in Table 1 (Figure 4C). Other species were calculated in a similar way, utilising tissue mass and molecular mass. The initial steady state levels of many other intermediate species were assumed. Each value is in $\mathrm{mg} /$ compartment. Table A.2 provides the details of the species and their abbreviations, while Table A.3 provides details of over 144 kinetic based reactions which in total make up the new version of the model. To summarise the kinetics, the model includes 37 reactions which are derived using the law of mass action, 58 reactions informed by Michaelis-Menten kinetics, 6 reversible reactions informed by MichaelisMenten kinetics, 9 bi, 3 ping pong bi-bi kinetic reactions, and 31 rate laws that were either part of the old model or developed during its adaptation. Each functional form is underpinned by the experimental literature, and examples of all the functional forms are provided within the ordinary differential equations (Appendix B). In order to parameterise the kinetic reactions summarised in Table A.3, firstly a comprehensive search of the enzyme functional data repository, BRENDA was conducted (http://www.brenda-enzymes.org/) (Chang et al., 2015). Many of the enzymes identified within BRENDA had a wide range of values. Suitable values were selected based on considering the biological source of the kinetic information. Some of the model parameters could not be located within BRENDA, therefore to obtain these parameters, literature searches were conducted using PubMed, Science Direct and Google Scholar. The source of each parameter is indicated in column 4 of Table A.4. For a number of parameters, no kinetic information could be obtained, therefore several assumptions were used, the details of these are also given in table A.4. The model was tuned until an 'optimal' set of parameters was obtained, which reflected the steady state values of key model outputs 
Table 1. Data used to calculate initial values of cholesterol in each compartment. See table A.2 for abbreviations.

\begin{tabular}{llllll}
\hline Species & Concentration & $\begin{array}{l}\text { Molecular } \\
\text { mass }\end{array}$ & $\begin{array}{l}\text { Location } \\
\text { Mass }(\mathrm{kg})\end{array}$ & $\begin{array}{l}\text { Calculated mass } \\
(\mathrm{mg})\end{array}$ & Reference \\
\hline & & & & & \\
$\mathrm{HFC}$ & $67.1 \mathrm{nmol} / \mathrm{mg}$ & 386.66 & 1.5 & $\begin{array}{l}38,917.329 \\
18,011.97\end{array}$ & Mc Auley et al. (2012) \& \\
$\mathrm{HCE}$ & $18.5 \mathrm{nmol} / \mathrm{mg}$ & 649.08 & & $\begin{array}{l}25,913.52 \\
\mathrm{PFC}\end{array}$ & $399.9 \mathrm{mg} / \mathrm{kg}$ \\
$\mathrm{PCE}$ & $65.1 \mathrm{mg} / \mathrm{kg}$ & - & 64.8 & $4,218.48$ & van de Pas et al. (2012) \\
& & & & & \\
\hline
\end{tabular}

Utilising a plasma volume of 2.79L (van de Pas et al., 2012), the initial steady state values of VLDL-C, LDL-C and HDL-C (Sharma et al., 2010), could be converted to $\mathrm{mg} /$ plasma (Table 2). Lipoprotein values were converted back to $\mathrm{mg} / \mathrm{dL}$ for analysis. When the model was simulated, VLDL-C, LDL-C and mean HDL-C values were consistent with these literature values (Figure 4D). Mean HDL-C was calculated from $\mathrm{HDL}_{2}$ and $\mathrm{HDL}_{3}$ and ndHDL-C subfractions. Cholesterol and unconjugated bile acids were steadily excreted at a rate of 0.1 and $0.05 \mathrm{mg} / \mathrm{hour}$ respectively (Figure 4E). The initial steady state values for bile acids were assumed. For bile acids contained in the hepatic tissue, a value of $220 \mathrm{mg}$ was utilised for those conjugated (HCBA). A value of $180 \mathrm{mg}$ was assigned to represent the unconjugated proportion (HUBA), and a value of $200 \mathrm{mg}$ was chosen to represent HUBA-CoA. Within the ileocytes, a value of $50 \mathrm{mg}$ was utilised for both the conjugated and unconjugated forms (ICBA and IUBA). Within the intestinal lumen a steady state value of $200 \mathrm{mg}$ was assumed to represent conjugated bile acids, while a value of $50 \mathrm{mg}$ represented the steady state level of unconjugated bile acids (LCBA and LUBA). Levels remained constant over time (Figure 4F).

Table 2. Data used to calculate the initial values of lipoproteins. See Table A.2 for abbreviations.

\begin{tabular}{lllll}
\hline Lipoprotein & $\begin{array}{l}\text { Concentration } \\
(\mathrm{mg} / \mathrm{dL})\end{array}$ & $\begin{array}{l}\text { Plasma Volume } \\
(\mathrm{L})\end{array}$ & $\begin{array}{l}\text { Calculated mass } \\
(\mathrm{mg})\end{array}$ & Reference \\
\hline & & & & \\
VLDL-C & 34 & 2.79 & 948.6 & Sharma et al. (2010) \& van \\
LDL-C & 115 & $3,208.5$ & de Pas et al. (2012) \\
HDL-C & 44 & & $1,227.6$ & \\
\hline
\end{tabular}


A)

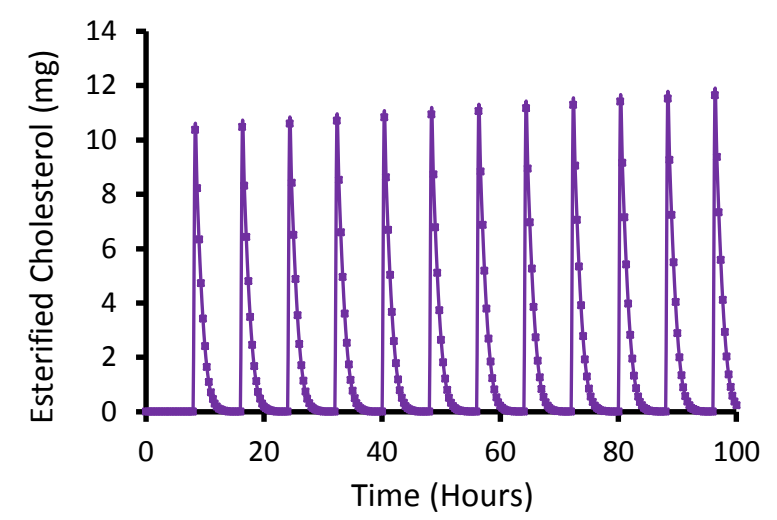

C)

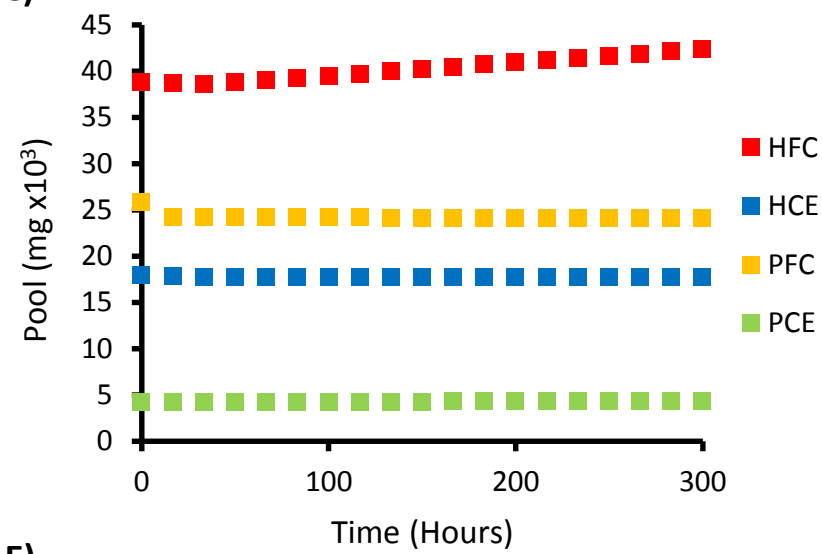

E)

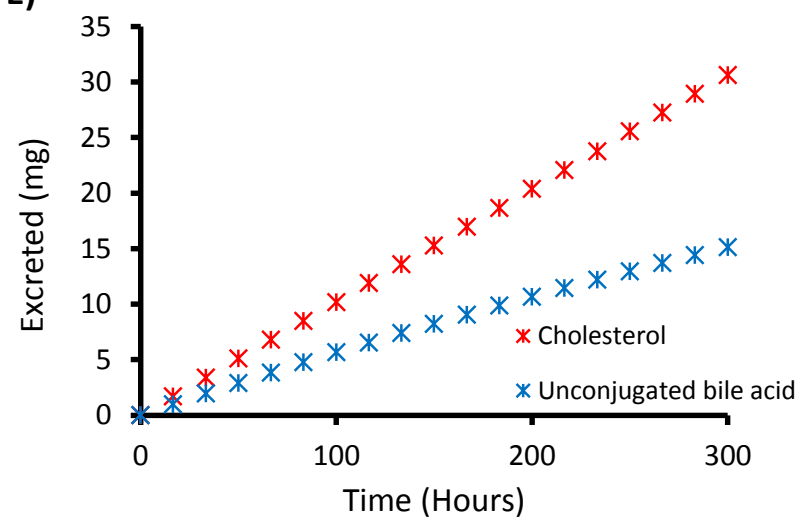

B)

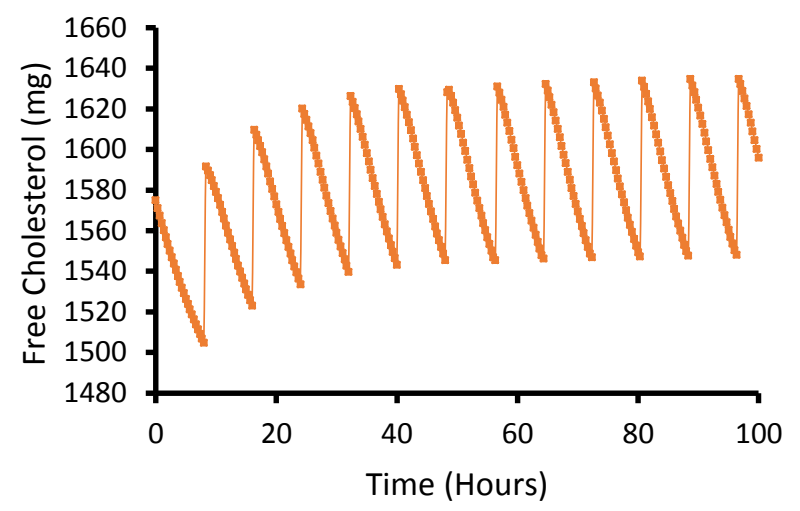

D)
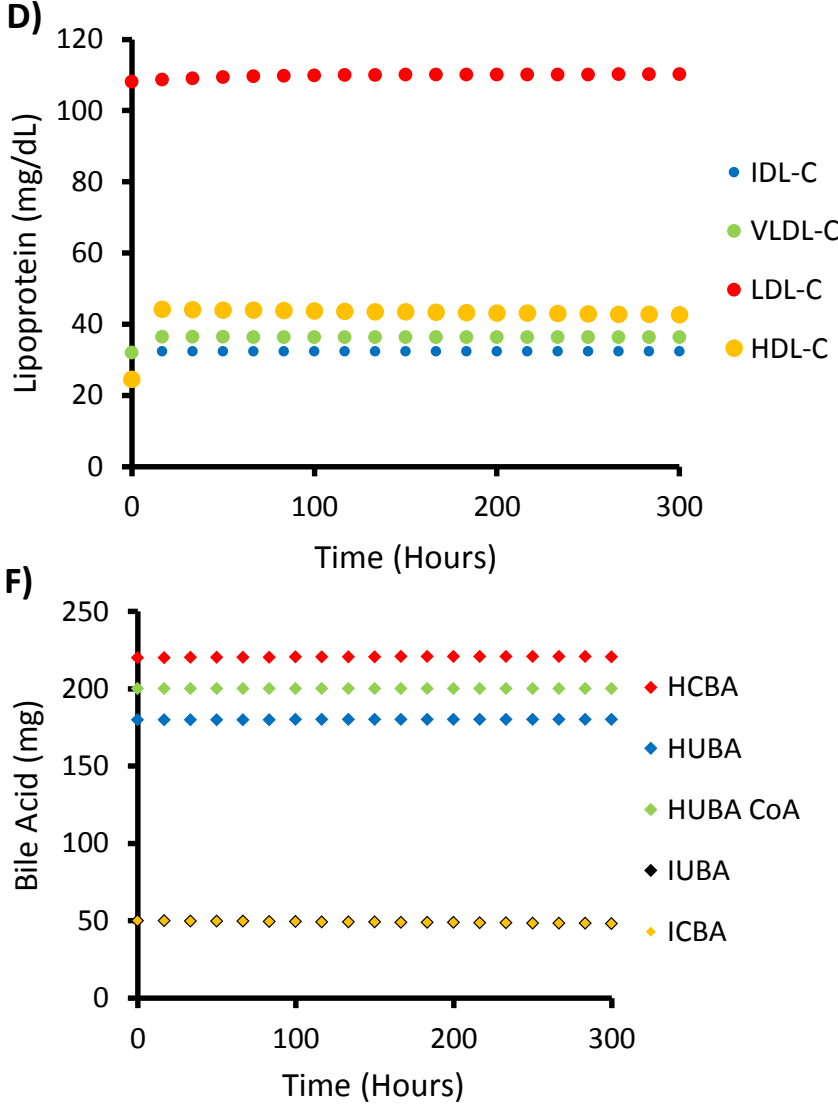

Figure 4. Model Outputs of A) ingestion of esterified cholesterol, B) jejunocyte pool of free cholesterol C) hepatic and peripheral pools of free and esterified cholesterol, D) lipoprotein profile E) excreted cholesterol and unconjugated bile acids and F) hepatic, ileocyte and intestinal lumen pools of conjugated and unconjugated bile acids. For D) mean HDL-C calculated from $\mathrm{HDL}_{2}, \mathrm{HDL}_{3}$ and ndHDL-C.

\subsection{Results}

\subsection{Initial Examination of the Model}

Initial simulations were performed to compare model output with our previous model. Figure 5 illustrates how several key variables compare to the original model. Over a 15 day period it was found that the average concentration of LDL-C, mean HDL-C and total cholesterol reduced by $11 \%, 20 \%$ and $0.6 \%$ respectively, when compared to the original model. Mean HDL-C was calculated from $\mathrm{HDL}_{2}, \mathrm{HDL}_{3}$ and ndHDL-C. In contrast, IDL-C and VLDL-C increased by $33 \%$ 
and $67 \%$ respectively in the updated model. The LDL-C:HDL-C ratio increased slightly from 2.52:1 in the original model to 2.77:1 in the updated model. Both of these ratios however are in line with current recommendations. A ratio $<3.0: 1$ and $<2.5: 1$ is optimal for males and females respectively, to reduce the risk of CVD onset (Millan et al., 2009).

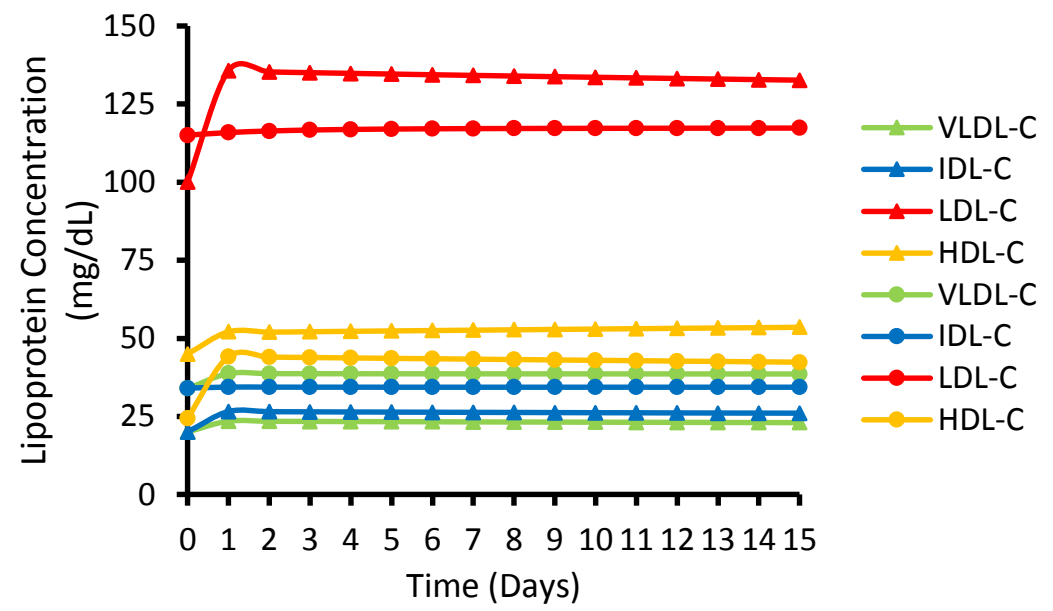

Figure 5. Comparison of the lipoprotein profile from the original and updated model. Model run for 15 days or equivalent $(21,600$ minutes). Circle markers represent the model output from the updated model. Triangle markers represent the lipoprotein profile from the Mc Auley et al. (2012) model. HDL$\mathrm{C}$ from the updated model is the mean average of $\mathrm{HDL}_{2}, \mathrm{HDL}_{3}$ and ndHDL-C.

\subsection{Dietary Cholesterol Ingestion}

Individual differences exist in cholesterol metabolism from one individual to the next (Herron et al., 2003). This is emphasised by DC feeding studies which demonstrate notable differences in the response to DC from one individual to individual. Herron et al. (2003) demonstrated that hypo-responders could ingest $\sim 640 \mathrm{mg} /$ day of cholesterol with no effect on LDL-C or HDL-C levels. In contrast, hyper-responders exhibited a $30 \%$ increase in LDL-C and an $8 \%$ increase in HDL-C (Herron et al., 2003). To determine if the model behaves as a hypo- or hyper-responder, fold increases of $0.5,1,2$, and 3 were applied to both ingested free and esterified DC. To do this the events for DC ingestion were modified. For the 0.5 -fold analysis, $44.335 \mathrm{mg}$ of free cholesterol and $6.3335 \mathrm{mg}$ of esterified cholesterol were ingested 3 times a day. Whereas an increase to $266.001 \mathrm{mg}$ of free cholesterol and $38.001 \mathrm{mg}$ of esterified cholesterol was ingested 3 times a day for a 3-fold dietary increase. A 2-fold increase in DC resulted in an increase of $0.0012 \%(0.0014 \mathrm{mg} / \mathrm{dL})$ in LDL-C, $(>1000$ hours). No change in mean HDL-C levels were observed (data not shown). A 2-fold increase in DC resulted in a $23.7 \%$ increase in HFC, and a negligible increase of $0.0002 \%$ in HCE. No difference in PFC or PCE was observed (Figure 6A).

\subsection{Comparison with Clinical data}

Both the original and updated models were compared to clinical data from a DC feeding study (Figure 6B). After a comprehensive literature search in this area, the most suitable time course data that could be obtained was from a healthy 31 year old normocholesterolaemic male that underwent an 11 week high cholesterol diet (1000mg/day) (Lin and Connor, 1980). The purpose of using this data, which clearly shows a hyper-response to DC, was to provide a comparison between this and our models. To compare the model to the clinical data, the intake of cholesterol was raised to $1000 \mathrm{mg}$ per day, and baseline LDL-C was reduced to $66.32 \mathrm{mg} / \mathrm{dL}$. To recreate a $1000 \mathrm{mg} /$ day cholesterol intake, the events were altered to reflect an intake of $291.667 \mathrm{FC}$ and $41.667 \mathrm{mg}$ CE 3 times a day. Lin and Connor (1980) did not report LDL-C or HDL-C values, therefore LDL-C was calculated from total cholesterol and triglyceride values using the equation below, in which LDL-C can be calculated in the absence of HDL-C data (Anandaraja et al., 2005). 


$$
\text { Calculated } L D L-C=(0.9 \times \text { Total Cholesterol })-\frac{0.9 \times \text { triglycerides }}{5}-28
$$

When the daily rate of cholesterol ingestion was raised, LDL-C increased from an initial value of $66.32 \mathrm{mg} / \mathrm{dL}$, to a steady state value of $115 \mathrm{mg} / \mathrm{dL}$ after one week. It is important to note this is the behaviour of LDL-C regardless of the rate of dietary cholesterol ingestion. This finding contrasts with the original model's response during this feeding regime, where LDL-C continues to rise after week one. It is feasible the behaviour of the updated model is biologically plausible, as several decades of experimental work in this area have suggested that cholesterol metabolism is tightly regulated in the majority of individuals, with hypo-responders known to exhibit a negligible lipoprotein response (Herron et al., 2003; Jones et al., 1996; Quintao et al., 1971). Consequently, it was important to establish which regulatory mechanisms responded effectively in the model to inhibit a rise in lipoprotein cholesterol. After examining the simulation data it was found a key regulatory mechanism which adapted to this increase in DC was cholesterol excretion (EFC). EFC increased by $25.1 \%$ by the end of the 11 week period. In addition to the compensatory effect of excreted cholesterol, intestinal and hepatic cholesterol also increased. It was found high DC resulted in the pool of CE in the intestinal lumen (LCE) increasing to $5.97 \mathrm{mg}$ after 11 weeks. This contrasted with a value of $0.15 \mathrm{mg}$ after a 'normal' cholesterol feeding regime over the same time period. LFC also increased by $4.75 \%$ as a result of this simulation. The amount of absorbed cholesterol, in the jejunocytes also increased; JFC and JCE levels were 24.41 and $0.03 \%$ higher respectively after the cholesterol feeding. In addition, HFC increased by $85.25 \%$, while the increase in HCE was negligible $(0.0005 \%)$. Bile acid levels and LDLr activity/number were unaffected during cholesterol feeding, which could account for the substantial cholesterol accumulation within the hepatic tissue, and marginal LDL-C response.
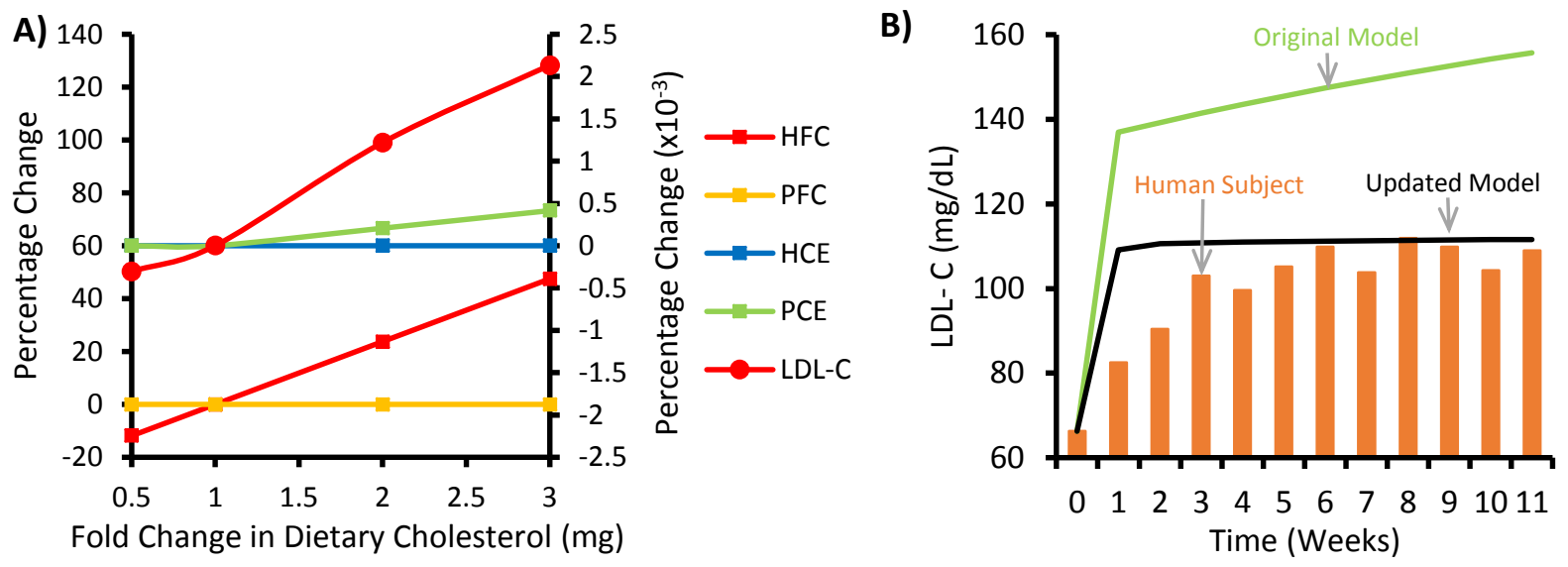

Figure 6. Cholesterol Ingestion Analysis. A) Response of LDL-C and cholesterol pools in the updated model to fold-change increases in dietary cholesterol after 1000 hours. HFC, hepatic free cholesterol; PFC, peripheral free cholesterol (left axis); HCE, hepatic cholesterol esters; PCE, peripheral cholesterol esters; and LDL-C (right axis). B) Goodness of fit of model to clinical data. Comparison of LDL-C concentration in response to simulated cholesterol feeding in the Mc Auley et al. (2012), and the updated model, with a human cholesterol feeding study. A $1000 \mathrm{mg}$ dose of cholesterol was ingested per day by a human subject and induced in both models for an 11 week trial period and the LDL-C monitored. Baseline LDL-C of both models was set at $66.32 \mathrm{mg} / \mathrm{dL}$ to match clinical data. Black line represents updated model the green line represents the Mc Auley et al. (2012) model, and the orange bar represents the LDL-C response to cholesterol feeding in a human subject (Lin and Connor, 1980).

\subsection{Acute daily ingestion of saturated fat}

Diets high in SFA are associated with raised plasma cholesterol levels. High levels of SFA lead to an increase in LDL-C by three possible mechanisms. 1) LDL-C clearance rate, as SFA 
supresses LDLr activity (Woollett et al., 1992). 2) There is an increase in the rate of cholesterol synthesis (Jones et al., 1994). 3) Modulation of RCT occurs (Berard et al., 2004; Jansen et al., 2000). RCT is affected in 2 ways. Firstly, CETP is upregulated, thus transporting esterified cholesterol from HDL-C to LDL-C and VLDL-C at an increased rate (Jansen et al., 2000). Secondly, LCAT is inhibited which reduces the esterification of cholesterol in HDL-C. This reduces the concentration gradient for the transfer of cholesterol from the peripheral tissues to HDL. To replicate SFA intake variations, 7 parameters were altered simultaneously (Table 3). This analysis resulted in increases to LDL-C, HCE and PCE levels, whereas HDL-C decreased (Figure 7). LDL-C, HCE, and PCE increased 1.7, 0.4 and $0.5 \%$ respectively for the 2 foldanalysis. There was no effect on hepatic and peripheral free cholesterol (HFC and PFC) after 1000 hours.

Table 3. Summary of parameters involved in fold analysis of SFA intake.

\begin{tabular}{|c|c|c|c|c|c|c|}
\hline \multirow{2}{*}{\multicolumn{2}{|c|}{ Reaction }} & \multirow{3}{*}{$\frac{\text { Parameter }}{\text { Kndl3 }_{\text {hal }}}$} & \multicolumn{4}{|c|}{ Fold Change } \\
\hline & & & \multirow{2}{*}{$\begin{array}{l}0.5 \\
8 \times 10^{-4}\end{array}$} & \multirow{2}{*}{1} & \multirow{2}{*}{$\begin{array}{l}2 \\
2 \times 10^{-4}\end{array}$} & \multirow{2}{*}{$\begin{array}{l}3 \\
1.33 \times 10^{-4}\end{array}$} \\
\hline 36 & LCAT activity & & & & & \\
\hline 39 & $\begin{array}{l}\text { CETP mediated transfer to } \\
\text { VLDL }\end{array}$ & $\mathrm{K}_{\text {cetp2 }}$ & $5 \times 10^{-8}$ & $1 \times 10^{-7}$ & $2 \times 10^{-7}$ & $3 \times 10^{-7}$ \\
\hline 40 & $\begin{array}{l}\text { CETP mediated transfer to } \\
\text { LDL }\end{array}$ & $\mathrm{K}_{\text {cetp1 }}$ & $5 \times 10^{-8}$ & $1 \times 10^{-7}$ & $2 \times 10^{-7}$ & $3 \times 10^{-7}$ \\
\hline 60 & LDLr degradation & $\mathrm{K}_{1}$ & $5 \times 10^{-8}$ & $1 \times 10^{-7}$ & $2 \times 10^{-7}$ & $3 \times 10^{-7}$ \\
\hline 78 & Hepatic acetyl CoA synthesis & $\mathrm{K}_{1}$ & 0.5 & 1 & 2 & 3 \\
\hline 96 & $\begin{array}{l}\text { Peripheral acetyl CoA } \\
\text { synthesis }\end{array}$ & $\mathrm{K}_{1}$ & $5 \times 10^{-6}$ & $1 \times 10^{-5}$ & $2 \times 10^{-5}$ & $3 \times 10^{-5}$ \\
\hline 114 & $\begin{array}{l}\text { Intestinal acetyl CoA } \\
\text { synthesis }\end{array}$ & $\mathrm{K}_{1}$ & 0.5 & 1 & 2 & 3 \\
\hline
\end{tabular}

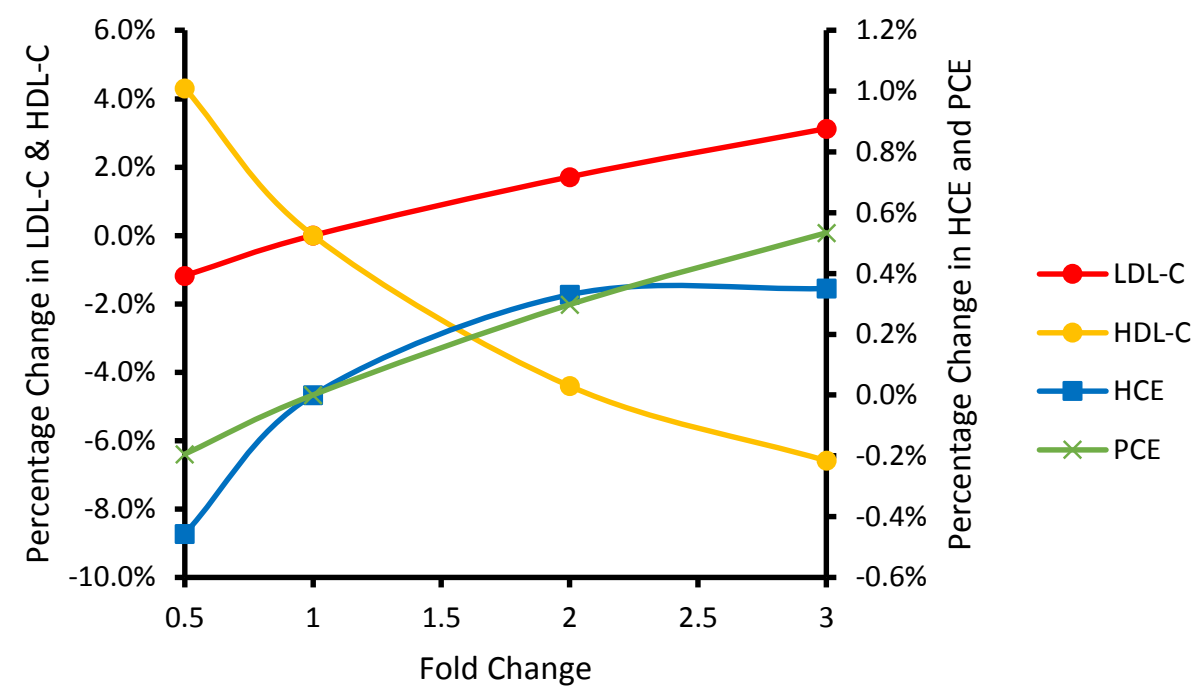

Figure 7. Fold change analysis of dietary SFA. The percentage change in LDL-C, HDL-C (left axis), HCE and PCE (right axis) monitored with fold changes to SFA intake. A total of 7 parameters were modified in the fold change analysis to represent an equivalent change in dietary SFA. To represent an increase in dietary SFA, increases to the rate of LDLr degradation, cholesterol synthesis and CETP mediated transport, and decreases to the LCAT mediated cholesterol esterification were conducted. Measurements recorded at 1000 hours. 


\subsection{Local Sensitivity Analysis}

To gain further insight into the robustness of the model a sensitivity analysis (SA) was performed. A robust model is resilient to relatively small perturbations in parameter values. Therefore given the lack of sensitivity of our model during our initial investigations the aim of the SA was to investigate the effect of both local and global parameter changes on model outputs, in particular LDL-C, and to identify critical parameter inputs. We firstly completed a local SA and calculated the sensitivity coefficients $\left(S_{i}\right)$ for each of the parameters of the model. To do this we removed the discrete feeding events and replaced them with a continuous feed for both DC and DFC. Appendix C gives the percentage change in output values for a $1 \%$ change in each of the 266 model parameters and ranks them by sensitivity, while Figure 8 presents the 10 most sensitive parameters of this analysis.

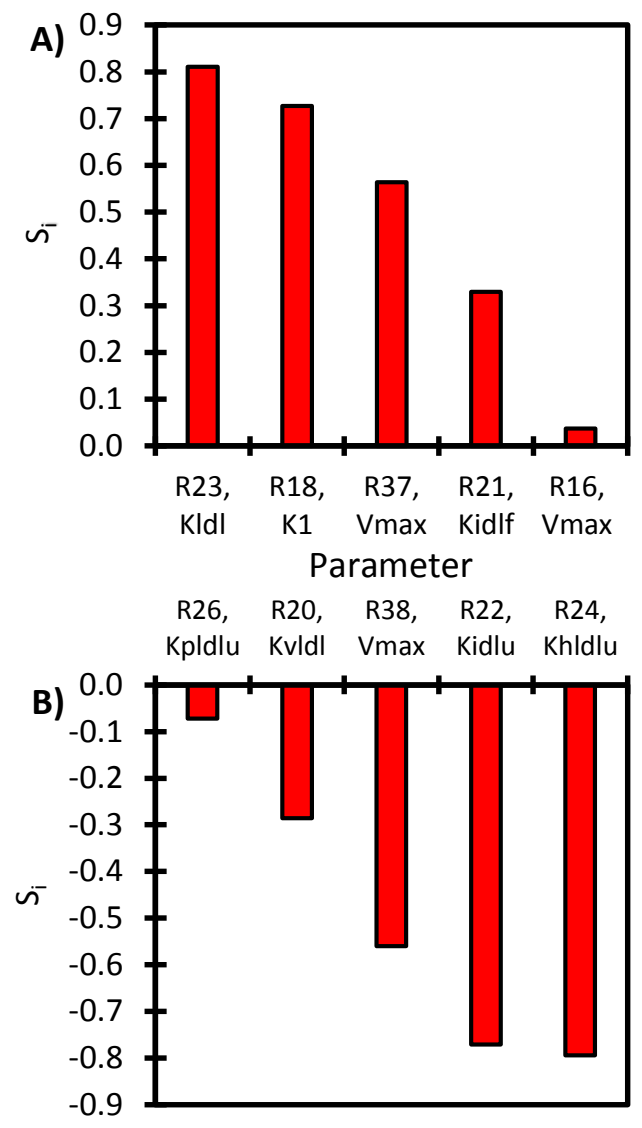

Figure 8 . The 10 most sensitive parameters. $S_{i}$, sensitivity index, percent change in LDL-C for a $1 \%$ change in model parameters; $R$, reaction. See Table A.3 for reaction details. 


\subsection{Global analysis}

Given the uncertainty surrounding a number of the parameter values, especially those associated with the less well characterised aspects of cholesterol metabolism, it is apparent that any inferences from our local sensitivity analysis should be interpreted with caution. Therefore, we deemed that it would be appropriate to conduct a global sensitivity analysis. A global sensitivity analysis attempts to mitigate this problem by examining model parameters in broader regions of parameter space. The rate constant for hepatic LDLr degradation was selected as our parameter of interest for the global scan (reaction 60 in Table A.3). This parameter was selected as the experimental literature suggests this is an important parameter for maintaining cholesterol homeostasis, and the reduction in hepatic LDLr numbers and/or activity has been associated with intrinsic ageing (Field and Gibbons, 2000). Furthermore, of the mechanisms associated with ageing, this parameter was most sensitive (see appendix $\mathrm{C}$ ). As no priori data was available on this parameter, it was determined that an appropriate sampling choice would be based on a uniform probability density function (Marino et al., 2008). Figure 9 presents the results from a global sensitivity analysis, where random samples were taken over a range of a 2 fold increase and decrease in the default value for this rate constant, with A) all "known" parameters scanned and unknown parameters fixed, B) all unknown parameters scanned and "known" parameters fixed, and C) all parameters scanned simultaneously, at 250 hours $(\mathrm{N}=500)$. See appendix $\mathrm{C}$ for a list of the scanned parameters for each of these simulations. Each scanned parameter had random samples taken between a 2 fold increase and decrease of its default value. The variability of LDL-C was small when 151 "known" parameters were scanned, and 113 unknown parameters remained fixed. The results show that LDL-C varied $\sim 2 \mathrm{mg} / \mathrm{dL}$ for any value of the rate constant for hepatic LDLr degradation between a 2 fold increase and decrease from its default value (Figure 9A). In contrast, LDL-C varied by $\sim 500 \mathrm{mg}$ when the "known" parameters were fixed and the unknown parameters scanned. Consequently the relationship between hepatic LDLr degradation and LDL-C was lost (Figure 9B). When all 266 parameters were scanned (including the 2 parameters used for the counter reactions for DFC and DCE intake), the range of LDL-C values remained similar. A marginal further reduction in $\mathrm{R}^{2}$ was also observed (Figure 9C). The significant difference in LDL-C variation when scanning parameters with well characterised kinetics versus parameters with assumed parameter values suggests the unknown parameters influence the behaviour of the model significantly. Moreover, the large range in LDL-C when unknown parameters were scanned, reinforces our finding from the local sensitivity scan, that parameters with assumed kinetics were most sensitive. 

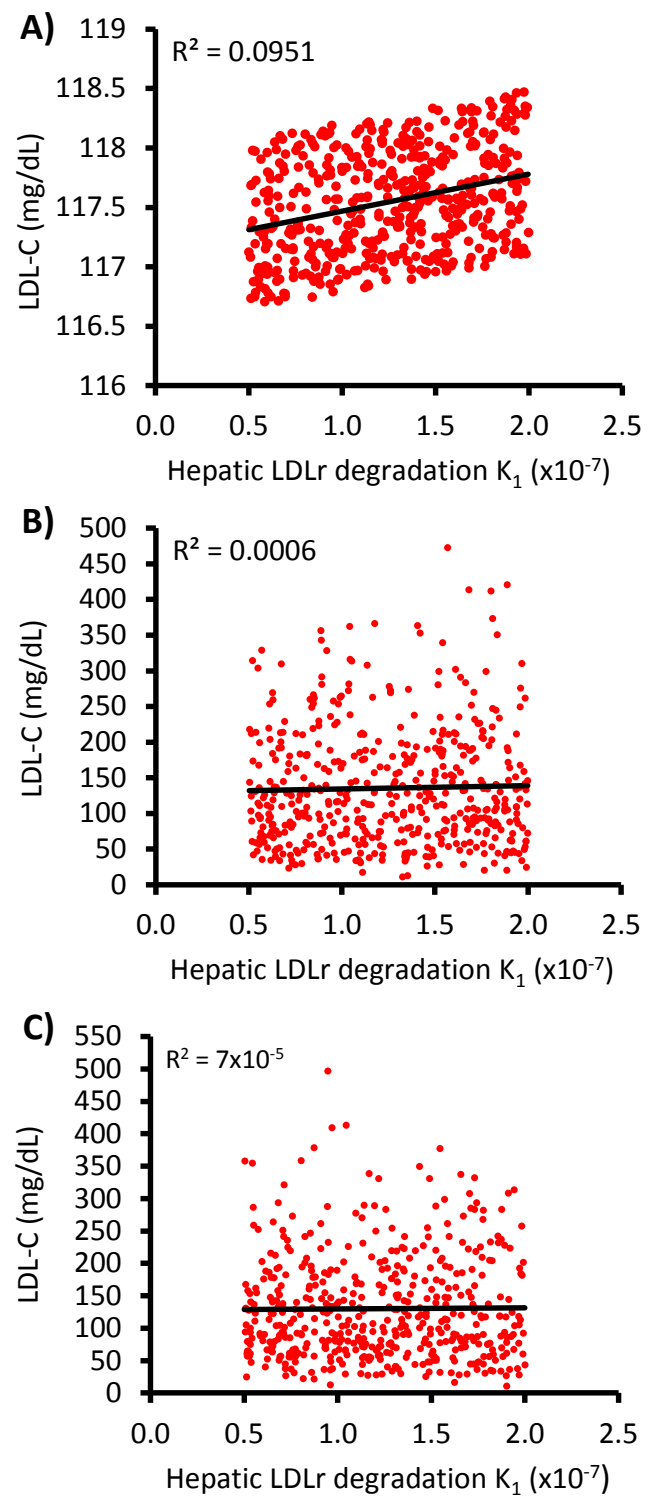

Figure 9. Global sensitivity analysis of parameter $K_{1}$, hepatic LDLr degradation. Role of parameter $K_{1}$ for hepatic LDLr degradation (reaction 60) with $A$ ) all unknown, assumed, and adapted parameters fixed, B) all "known" parameters fixed, and C) all parameters scanned. Non-fixed parameters were analysed between a 2-fold increase and decrease of that parameter value; calculated at 250 hours, $N=500 . R^{2}=$ Coefficient of determination. See section 5.6 for details of each figure. 


\subsection{Ageing}

As previously discussed, the ageing process affects many of the key mechanisms involved in cholesterol metabolism. Specifically, there is 1) an age-related decline in hepatic LDLr and subsequent reduction in LDL-C clearance (Millar et al., 1995), 2) an increase in cholesterol absorption (Duan et al., 2006), 3) a decline of BSH-positive intestinal microflora, such Lactobacillus and Bifidobacterium species (Hopkins and Macfarlane, 2002), and 4) a decline in bile acid synthesis (Bertolotti et al., 2007). To represent the ageing process, 4 parameters were modified. These modifications were a 2-fold decrease to the rate of NPC1L1 degradation, bacterial deconjugation, and CYP7AI activity. In addition, the rate of LDLr degradation was increased 2-fold (Table 4). The inverse of this analysis, was assumed to represent a young individual.

Table 4. Summary of parameters involved in the ageing analysis.

\begin{tabular}{llllll}
\hline \multirow{2}{*}{ Reaction } & \multirow{2}{*}{ Parameter } & \multicolumn{3}{c}{ Age group } \\
\cline { 4 - 5 } & & Young & Default & Old \\
\hline 45 & Bile acid Deconjugation & $\mathrm{V}_{\max }$ & $1 \times 10^{-5}$ & $5 \times 10^{-6}$ & $2.5 \times 10^{-6}$ \\
54 & NPC1L1 degradation & $\mathrm{K}_{1}$ & $2 \times 10^{-7}$ & $1 \times 10^{-7}$ & $5 \times 10^{-8}$ \\
60 & LDLr degradation & $\mathrm{K}_{1}$ & $5 \times 10^{-8}$ & $1 \times 10^{-7}$ & $2 \times 10^{-7}$ \\
132 & CYP7Al activity & $\mathrm{V}_{\max }$ & $1.11358 \times 10^{-3}$ & $5.5679 \times 10^{-4}$ & $2.78395 \times 10^{-4}$ \\
& & & & & \\
\hline
\end{tabular}

By simultaneously conducting a 2 -fold decrease to the parameters $\mathrm{K}_{\text {cetp } 1}$ and $\mathrm{K}_{\text {cept2, a CETP }}$ genotype such as $1405 \mathrm{~V}$ could also be replicated (reactions 40 and 39 respectively, Table A.3). $\mathrm{A}-2$ fold increase in $\mathrm{K}_{\mathrm{cept} 1}$ and $\mathrm{K}_{\mathrm{cept} 2}$ was also conducted to replicate a genotype reflective of a genetic predisposition for atherogenesis. These CETP genotypes were applied to each age category and LDL-C was recorded after 1000 hours (Figure 10). The ageing process resulted in an increased LDL-C for all CETP genotypes. The ageing process, in the presence of the genotype representing high CETP activity, resulted in a $1.6 \%$ increase in LDL-C. Similarly, the normal CETP genotype also produced a $1.6 \%$ increase in LDL-C with ageing. The CETP 1405V genotype however resulted in a less significant rise $(0.6 \%)$ in LDL-C with the ageing process. By contrasting the genotypes within each age category, the beneficial effects of the CETP I405V genotype were further substantiated. This advantageous genotype was more obvious in the aged category than the youth and normal categories. A $1.63 \%$ reduction in LDL-C was observed in the aged category, compared to a $0.64 \%$ reduction in both the normal and youth category. On the contrary, the effect of a genetic predisposition to atherosclerosis, was more apparent in the youth and normal categories, than the aged category, although this was negligible $(0.617$, 0.617 and $0.616 \%$ respectively). 


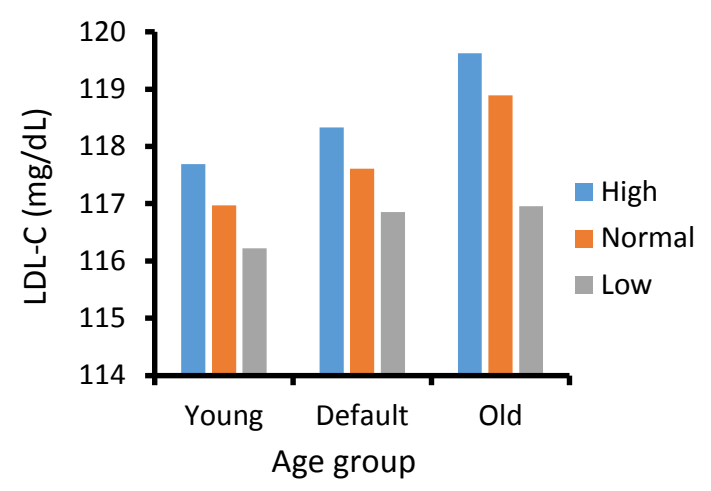

Figure 10. Role of CETP genotypes on LDL-C with ageing. To mimic an aged individual, a 2 fold increase in LDLr degradation, and a 2 fold decrease in NPC1L1 degradation, bile acid deconjugation, and CYP7AI activity was applied. For the youth analysis, the inverse of this protocol was conducted. A 2 fold increase or decrease in CETP activity was then applied to each group. High (blue), normal (orange), and low (grey) CEPT activities examined. LDL-C measured at 1000 hours.

\subsection{Discussion}

We have updated a whole-body mathematical model of cholesterol metabolism. The updated model includes 96 additional mechanisms, and has been deposited in the BioModels database (MODEL1508170000). In contrast to the original model, this model is significantly less sensitive to cholesterol feeding, and can be categorised as a hypo- rather than hyper-responder to cholesterol ingestion. This finding is perhaps unsurprising in light of experimental evidence which suggests $62.5 \%$ of healthy normocholesterolaemic males exhibit a hypo-response to dietary cholesterol (Herron et al., 2003). Moreover, it is widely regarded that cholesterol metabolism adapts to cholesterol feeding by invoking two major compensatory regulatory mechanisms, these are an increase in cholesterol excretion, and a decrease in whole-body cholesterol biosynthesis (Quintao et al., 1971). When there is effective feedback control mechanisms this can result in dietary cholesterol failing to illicit a response in lipoprotein metabolism. For instance, McNamara et al. (1987) demonstrated using 12 week studies that both low and high levels of dietary cholesterol did not induce significant increases in mean levels of plasma total, LDL, or HDL cholesterol. Moreover, there was no relationship between baseline plasma cholesterol levels and sensitivity to a dietary cholesterol challenge (McNamara et al., 1987).

In our model, clearly LDL-C did not rise, however both hepatic free cholesterol and intestinal cholesterol increased significantly during high cholesterol feeding. In the seminal work by Quintao et al. (1971) it is postulated that cholesterol feeding in humans is primarily controlled by one compensatory mechanism - an increase in cholesterol excretion, but not bile acid excretion, our model helps to substantiate this claim. Intriguingly, the authors also suggest that when there is an accumulation of cholesterol in the body pools, the effects on lipoprotein levels are insignificant, regardless of the quantity of cholesterol absorbed. This appears to be the case in humans, as regulatory processes inhibit an increase in lipoprotein cholesterol when body pools accumulate. Model organisms have also shown that body pools of cholesterol can increase significant as a result of cholesterol feeding. Ohtani et al. (1990) suggest that, in hamsters, an additional $0.1 \%$ dietary cholesterol is enough to induce the accumulation of cholesterol in the liver through the chylomicron remnant pathway (Ohtani et al., 1990). Wang et al. (2010) also reported that concentrations of the hepatic total cholesterol increased $\sim 4$-fold by with a $1 \%$ increase in dietary cholesterol in rats (Wang et al., 2010). 
Although the increases in the pools of cholesterol in our model, is similar to what has been reported experimentally, this could also suggest that our regulatory mechanisms may not be sufficiently adequate to deal with the excess cholesterol. One mechanism in this model that may need to be improved is the turnover of LDLr. In the updated model, an increase in dietary cholesterol, did not elicit a decrease in LDLr number. This contrasted with the previous model. This is an important point that needs to be emphasised, Hennessey et al. (1992) have demonstrated that a high intake of dietary cholesterol suppresses hepatic LDLr mRNA by $29 \%$ in cebus monkeys (Hennessy et al., 1992). Conversely, Spady and Cuthbert (1992) observed that rats on fed high levels of dietary cholesterol, did not exhibit suppressed hepatic LDLr activity despite a 350-fold increase in hepatic cholesterol ester levels (Spady and Cuthbert, 1992). More recently, Boone et al. (2011) found that LDLr expression in Sprague-Dawley rats was not altered by dietary cholesterol. There was also a significant increase in mean hepatic cholesterol and paradoxically a decrease in serum cholesterol (Boone et al., 2011). However, other studies in humans, such as Lichtenstein et al. (1993) demonstrate that the addition of dietary cholesterol ( 1.5 eggs per/day) to a corn oil-diet, can result in a significant increase in concentrations of total cholesterol $(6 \%)$, LDL-C (8\%), and HDL-C (7\%), when compared to diets with low dietary cholesterol, in 14 middle-aged and older individuals. Studies such as this consolidate the view that LDLr activity is downregulated in response to cholesterol feeding. Despite the lack of sensitivity of lipoprotein metabolism to cholesterol feeding, our model was sensitive to increases in dietary SFA. This finding is in line with the experimental literature as dietary SFA has been shown clinically to have a more profound effect on cholesterol metabolism than dietary cholesterol (He and Fernandez, 1998; Herron et al., 2003).

Large inter-individual differences in cholesterol metabolism, can in part be explained by genetic factors. For example, the $1405 \mathrm{~V}$ genotype is associated with longevity and reduced levels of CETP. This results in larger LDL-C and HDL-C particle size, in addition to reduced levels of LDL-C and increased HDL-C. This genotype is related to lower prevalence of hypertension, CVD, diabetes mellitus and metabolic syndrome (Atzmon et al., 2005; Barzilai et al., 2003). The role of a CETP genotype for reduced CETP, such as $1405 \mathrm{~V}$, in reducing the risk of ageassociated disease, was consolidated with our simulations. It was demonstrated that increased CETP activity resulted in raised LDL-C in all age groups. Conversely, decreased CETP activity, led to a lower LDL-C in all age categories. Furthermore, the age-related increase in LDL-C was reduced with the presence of the $1405 \mathrm{~V}$ genotype $(0.6 \% \mathrm{vs} .1 .6 \%)$. Although it is important to note that a reduction in CETP levels and subsequent increase in HDL-C, either due to a genetic polymorphism or pharmaceutical intervention, has been associated with an increase in mortality rate (Barter et al., 2007; Zhong et al., 1996). It is therefore important that the findings from this work, and other studies, are fully evaluated before in vivo application.

An important finding from our updated model was that the parameter values associated with the less well characterised aspects of cholesterol metabolism were particularly sensitive to changes in their values. Moreover, the cholesterol biosynthesis pathway, which has been well characterised, was a particularly robust part of the model. These findings from our local sensitivity analysis were supported by our global sensitive analysis, which demonstrated the increase in variation in LDL-C when unknown parameters were scanned, compared with known parameters. Therefore, we also have to consider the fact that the functional forms we have used to represent the interactions in our model may need further improvements, and that interactions may be due to many components of the model, such as RCT, lipoprotein dynamics and the enterohepatic circulation of bile acids, being poorly understood from a kinetic perspective.

There are a number of aspects of the model that could be developed in the future. For example, when conjugated and unconjugated bile acid levels are in a steady state, the $V_{\text {max }}$ value for the deconjugation of bile acids was significantly lower than that reported in the experimental literature (reaction 45 Table A.3). For example, for the intestinal bacteria Clostridium perfringens, Bacteriodes fragilis and Lactobacilli have suggested $V_{\max }$ values of $0.05,38.4$ and $25.4 \mathrm{mg} / \mathrm{min} / \mathrm{mg}$. However, a far lower $V_{\max }$ value of $5 \times 10^{-6}$ was used in the model (GopalSrivastava and Hylemon, 1988; Lundeen and Savage, 1992; Stellwag and Hylemon, 1976). Areas such as cholesterol and bile acid synthesis could also be further developed to incorporate less well understood mechanisms that have not been included in the model. Furthermore, this model could be combined with other pre-existing models, or further developed to include other 
compartments such as the gallbladder, or other interconnected metabolic pathways such as fatty acid or carbohydrate metabolism, or cortisol homeostasis. For example, cortisol is synthesised from cholesterol and is involved in provoking the breakdown of lipids, and a wide variety of other metabolites, therefore this model could be connected to a previously developed computational model of whole-body cortisol metabolism (Mc Auley et al., 2013; McAuley et al., 2009).

\subsection{Conclusions}

In combination with our previous model, the updated model presented here emphasises the important role of intrinsic ageing in disrupting whole-body cholesterol metabolism. Constructing this model has revealed a number of findings. Firstly, simulations indicated that the model is a hypo-responder to cholesterol feeding, but is sensitive to simulated SFA feeding. Secondly, the model tentatively supports that genotypes such as $1405 \mathrm{~V}$ has a protective role in healthy ageing. The model also highlights the robustness of the cholesterol biosynthesis pathway, and suggests key areas where experimental work needs to focus in the future. This study has highlighted the need for kinetic data in several key areas of cholesterol metabolism, including RCT, lipoprotein dynamics and the enterohepatic circulation of bile acids. As these areas could provide potential therapeutic targets for lowering cholesterol, we believe that a more in depth understanding of this process could lead to novel interventions in the future. Finally, this work has demonstrated the important role computational systems biology has to play in improving our understanding of lipid metabolism and health-span.

\section{Acknowledgements}

A.E. Morgan would like to acknowledge the Faculty of Science and Engineering at the University of Chester, for providing her with a studentship. We would also like to acknowledge the reviewers for their helpful suggestions.

\section{References}

Abbott, R.D., Garrison, R.J., Wilson, P.W., Epstein, F.H., Castelli, W.P., Feinleib, M., LaRue, C., 1983. Joint distribution of lipoprotein cholesterol classes. The Framingham study. Arteriosclerosis 3, 260-272.

Ajouz, H., Mukherji, D., Shamseddine, A., 2014. Secondary bile acids: an underrecognized cause of colon cancer. World J Surg Oncol 12, 164.

Al-Sheraji, S.H., Ismail, A., Manap, M.Y., Mustafa, S., Yusof, R.M., Hassan, F.A., 2012. Hypocholesterolaemic effect of yoghurt containing Bifidobacterium pseudocatenulatum G4 or Bifidobacterium longum BB536. Food Chemistry 135, 356-361.

Anandaraja, S., Narang, R., Godeswar, R., Laksmy, R., Talwar, K.K., 2005. Low-density lipoprotein cholesterol estimation by a new formula in Indian population. International Journal of Cardiology 102, 117-120.

Appelman, Y., van Rijn, B.B., ten Haaf, M.E., Boersma, E., Peters, S.A.E., 2015. Sex differences in cardiovascular risk factors and disease prevention. Atherosclerosis 241, 211-218.

Atzel, A., Wetterau, J.R., 1993. Mechanism of microsomal triglyceride transfer protein catalyzed lipid transport. Biochemistry 32, 10444-10450.

Atzel, A., Wetterau, J.R., 1994. Identification of two classes of lipid molecule binding sites on the microsomal triglyceride transfer protein. Biochemistry 33, 15382-15388.

Atzmon, G., Rincon, M., Rabizadeh, P., Barzilai, N., 2005. Biological evidence for inheritance of exceptional longevity. Mechanisms of Ageing and Development 126, 341-345.

Austin, M.A., Breslow, J.L., Hennekens, C.H., Buring, J.E., Willett, W.C., Krauss, R.M., 1988. Low-density lipoprotein subclass patterns and risk of myocardial infarction. Jama 260, 1917-1921.

Baigent, C., Blackwell, L., Emberson, J., Holland, L.E., Reith, C., Bhala, N., Peto, R., Barnes, E.H., Keech, A., Simes, J., Collins, R., 2010. Efficacy and safety of more intensive lowering of LDL cholesterol: a meta-analysis of data from 170,000 participants in 26 randomised trials. Lancet 376, 1670-1681.

Baptissart, M., Vega, A., Maqdasy, S., Caira, F., Baron, S., Lobaccaro, J.-M.A., Volle, D.H., 2013. Bile acids: From digestion to cancers. Biochimie 95, 504-517.

Barter, P.J., Caulfield, M., Eriksson, M., Grundy, S.M., Kastelein, J.J.P., Komajda, M., Lopez-Sendon, J., Mosca, L., Tardif, J.-C., Waters, D.D., Shear, C.L., Revkin, J.H., Buhr, K.A., Fisher, M.R., Tall, A.R., Brewer, B., 2007. Effects of Torcetrapib in Patients at High Risk for Coronary Events. New England Journal of Medicine 357, 2109-2122.

Barzilai, N., Atzmon, G., Schechter, C., et al., 2003. UNique lipoprotein phenotype and genotype associated with exceptional longevity. JAMA 290, 2030-2040.

Batta, A.K., Salen, G., Rapole, K.R., Batta, M., Batta, P., Alberts, D., Earnest, D., 1999. Highly simplified method for gas-liquid chromatographic quantitation of bile acids and sterols in human stool. Journal of lipid research 40, 11481154.

Begley, M., Hill, C., Gahan, C.G., 2006. Bile salt hydrolase activity in probiotics. Appl Environ Microbiol 72, 1729-1738. 
Berard, A.M., Dabadie, H., Palos-Pinto, A., Dumon, M.F., Darmon, M., 2004. Reduction of dietary saturated fatty acids correlates with increased plasma lecithin cholesterol acyltransferase activity in humans. Eur J Clin Nutr 58, 881-887. Bertolotti, M., Abate, N., Bertolotti, S., Loria, P., Concari, M., Messora, R., Carubbi, F., Pinetti, A., Carulli, N., 1993. Effect of aging on cholesterol 7 alpha-hydroxylation in humans. Journal of lipid research 34, 1001-1007.

Bertolotti, M., Gabbi, C., Anzivino, C., Crestani, M., Mitro, N., Del Puppo, M., Godio, C., De Fabiani, E., Macchioni, D., Carulli, L., Rossi, A., Ricchi, M., Loria, P., Carulli, N., 2007. Age-related changes in bile acid synthesis and hepatic nuclear receptor expression. Eur J Clin Invest 37, 501-508.

Bhattacharya, B.S., Sweby, P.K., Minihane, A.M., Jackson, K.G., Tindall, M.J., 2014. A mathematical model of the sterol regulatory element binding protein 2 cholesterol biosynthesis pathway. Journal of theoretical biology 349, 150-162.

Boone, L.R., Brooks, P.A., Niesen, M.I., Ness, G.C., 2011. Mechanism of Resistance to Dietary Cholesterol. Journal of Lipids 2011, 9.

Brown, M.S., Goldstein, J.L., 1984. How LDL receptors influence cholesterol and atherosclerosis. Sci Am 251, 58-66. Chang, A., Schomburg, I., Placzek, S., Jeske, L., Ulbrich, M., Xiao, M., Sensen, C.W., Schomburg, D., 2015. BRENDA in 2015: exciting developments in its 25th year of existence. Nucleic acids research 43, D439-446.

Chapman, M.J., Le Goff, W., Guerin, M., Kontush, A., 2010. Cholesteryl ester transfer protein: at the heart of the action of lipid-modulating therapy with statins, fibrates, niacin, and cholesteryl ester transfer protein inhibitors. Eur Heart J 31 , 149-164.

Chirackal Manavalan, A.P., Kober, A., Metso, J., Lang, I., Becker, T., Hasslitzer, K., Zandl, M., Fanaee-Danesh, E., Pippal, J.B., Sachdev, V., Kratky, D., Stefulj, J., Jauhiainen, M., Panzenboeck, U., 2014. Phospholipid transfer protein is expressed in cerebrovascular endothelial cells and involved in high density lipoprotein biogenesis and remodeling at the blood-brain barrier. The Journal of biological chemistry 289, 4683-4698.

Cooney, M.T., Dudina, A., De Bacquer, D., Wilhelmsen, L., Sans, S., Menotti, A., De Backer, G., Jousilahti, P., Keil, U., Thomsen, T., Whincup, P., Graham, I.M., 2009. HDL cholesterol protects against cardiovascular disease in both genders, at all ages and at all levels of risk. Atherosclerosis 206, 611-616.

Cooper, A.D., 1997. Hepatic uptake of chylomicron remnants. Journal of lipid research 38, 2173-2192.

Cui, Q., Ju, X., Yang, T., Zhang, M., Tang, W., Chen, Q., Hu, Y., Haas, J.V., Troutt, J.S., Pickard, R.T., Darling, R., Konrad, R.J., Zhou, H., Cao, G., 2010. Serum PCSK9 is associated with multiple metabolic factors in a large Han Chinese population. Atherosclerosis 213, 632-636.

Demirezen, E.M., Barlas, Y., 2008. A simulation model for blood cholesterol dynamics and related disorders, The 27th International Conference of the System Dynamics Society, Albuquerque, New Mexico.

Duan, L.P., Wang, H.H., Ohashi, A., Wang, D.Q., 2006. Role of intestinal sterol transporters Abcg5, Abcg8, and Npc1l1 in cholesterol absorption in mice: gender and age effects. Am J Physiol Gastrointest Liver Physiol 290, G269-276.

Dujovne, C.A., Ettinger, M.P., McNeer, J.F., Lipka, L.J., LeBeaut, A.P., Suresh, R., Yang, B.o., Veltri, E.P., 2002. Efficacy and safety of a potent new selective cholesterol absorption inhibitor, ezetimibe, in patients with primary hypercholesterolemia. The American Journal of Cardiology 90, 1092-1097.

Ericsson, S., Eriksson, M., Vitols, S., Einarsson, K., Berglund, L., Angelin, B., 1991. Influence of age on the metabolism of plasma low density lipoproteins in healthy males. J Clin Invest 87, 591-596.

Field, P.A., Gibbons, G.F., 2000. Decreased hepatic expression of the low-density lipoprotein (LDL) receptor and LDL receptor-related protein in aging rats is associated with delayed clearance of chylomicrons from the circulation. Metabolism: clinical and experimental 49, 492-498.

Fu, Z.D., Csanaky, I.L., Klaassen, C.D., 2012. Gender-divergent profile of bile acid homeostasis during aging of mice. PLoS One 7, e32551.

Gerard, P., 2013. Metabolism of cholesterol and bile acids by the gut microbiota. Pathogens 3, 14-24.

Gillotte, K.L., Davidson, W.S., Lund-Katz, S., Rothblat, G.H., Phillips, M.C., 1998. Removal of cellular cholesterol by pre-beta-HDL involves plasma membrane microsolubilization. Journal of lipid research 39, 1918-1928.

Guo, C.F., Li, J.Y., 2013. Hypocholesterolaemic action of Lactobacillus casei F0822 in rats fed a cholesterol-enriched diet. International Dairy Journal 32, 144-149.

He, L., Fernandez, M.L., 1998. Saturated fat and simple carbohydrates elevate plasma LDL cholesterol concentrations by specific alterations on hepatic cholesterol metabolism. Nutrition Research 18, 1003-1015.

He, Y., Zhang, L., Li, Z., Gao, H., Yue, Z., Liu, Z., Liu, X., Feng, X., Liu, P., 2015. RIP140 triggers foam-cell formation by repressing ABCA1/G1 expression and cholesterol efflux via liver $X$ receptor. FEBS Lett 589, 455-460.

Hennessy, L.K., Osada, J., Ordovas, J.M., Nicolosi, R.J., Stucchi, A.F., Brousseau, M.E., Schaefer, E.J., 1992. Effects of dietary fats and cholesterol on liver lipid content and hepatic apolipoprotein A-I, B, and E and LDL receptor mRNA levels in cebus monkeys. Journal of lipid research 33, 351-360.

Herron, K.L., Vega-Lopez, S., Conde, K., Ramjiganesh, T., Shachter, N.S., Fernandez, M.L., 2003. Men Classified as Hypo- or Hyperresponders to Dietary Cholesterol Feeding Exhibit Differences in Lipoprotein Metabolism. The Journal of Nutrition 133, 1036-1042.

Hollander, D., Morgan, D., 1979. Increase in cholesterol intestinal absorption with aging in the rat. Exp Gerontol 14, 201-204.

Hoops, S., Sahle, S., Gauges, R., Lee, C., Pahle, J., Simus, N., Singhal, M., Xu, L., Mendes, P., Kummer, U., 2006. COPASI-a COmplex PAthway SImulator. Bioinformatics 22, 3067-3074.

Hopkins, M.J., Macfarlane, G.T., 2002. Changes in predominant bacterial populations in human faeces with age and with Clostridium difficile infection. Journal of Medical Microbiology 51, 448-454.

Hopkins, M.J., Sharp, R., Macfarlane, G.T., 2001. Age and disease related changes in intestinal bacterial populations assessed by cell culture, 16S rRNA abundance, and community cellular fatty acid profiles. Gut 48, 198-205.

Hovingh, G.K., Kastelein, J.J.P., van Deventer, S.J.H., Round, P., Ford, J., Saleheen, D., Rader, D.J., Brewer, H.B., Barter, P.J., 2015. Cholesterol ester transfer protein inhibition by TA-8995 in patients with mild dyslipidaemia (TULIP): a randomised, double-blind, placebo-controlled phase 2 trial. The Lancet.

Hubner, K., Schwager, T., Winkler, K., Reich, J.G., Holzhutter, H.G., 2008. Computational lipidology: predicting lipoprotein density profiles in human blood plasma. PLoS Comput Biol 4, e1000079.

Hucka, M., Finney, A., Bornstein, B.J., Keating, S.M., Shapiro, B.E., Matthews, J., Kovitz, B.L., Schilstra, M.J., Funahashi, A., Doyle, J.C., Kitano, H., 2004. Evolving a lingua franca and associated software infrastructure for computational systems biology: the Systems Biology Markup Language (SBML) project. Syst Biol (Stevenage) 1, 4153. 
Hucka, M., Finney, A., Sauro, H.M., Bolouri, H., Doyle, J.C., Kitano, H., Forum:, Arkin, A.P., Bornstein, B.J., Bray, D., Cornish-Bowden, A., Cuellar, A.A., Dronov, S., Gilles, E.D., Ginkel, M., Gor, V., Goryanin, I.I., Hedley, W.J., Hodgman, T.C., Hofmeyr, J.-H., Hunter, P.J., Juty, N.S., Kasberger, J.L., Kremling, A., Kummer, U., Le Novère, N., Loew, L.M., Lucio, D., Mendes, P., Minch, E., Mjolsness, E.D., Nakayama, Y., Nelson, M.R., Nielsen, P.F., Sakurada, T., Schaff, J.C., Shapiro, B.E., Shimizu, T.S., Spence, H.D., Stelling, J., Takahashi, K., Tomita, M., Wagner, J., Wang, J., 2003. The systems biology markup language (SBML): a medium for representation and exchange of biochemical network models. Bioinformatics 19, 524-531.

Ikeda, I., Matsuoka, R., Hamada, T., Mitsui, K., Imabayashi, S., Uchino, A., Sato, M., Kuwano, E., Itamura, T., Yamada, K., Tanaka, K., Imaizumi, K., 2002. Cholesterol esterase accelerates intestinal cholesterol absorption. Biochimica et Biophysica Acta (BBA) - General Subjects 1571, 34-44.

Iqbal, J., Hussain, M.M., 2009. Intestinal lipid absorption. Am J Physiol Endocrinol Metab 296, E1183-1194.

Jansen, S., Lopez-Miranda, J., Castro, P., Lopez-Segura, F., Marin, C., Ordovas, J.M., Paz, E., Jimenez-Pereperez, J., Fuentes, F., Perez-Jimenez, F., 2000. Low-fat and high-monounsaturated fatty acid diets decrease plasma cholesterol ester transfer protein concentrations in young, healthy, normolipemic men. Am J Clin Nutr 72, 36-41.

Jarocki, P., Podleśny, M., Glibowski, P., Targoński, Z., 2014. A New Insight into the Physiological Role of Bile Salt Hydrolase among Intestinal Bacteria from the Genus <italic>Bifidobacterium</italic>. PLoS ONE 9, e114379.

Jerby, L., Shlomi, T., Ruppin, E., 2010. Computational reconstruction of tissue-specific metabolic models: application to human liver metabolism. Mol Syst Biol 6, 401.

Ji, A., Meyer, J.M., Cai, L., Akinmusire, A., de Beer, M.C., Webb, N.R., van der Westhuyzen, D.R., 2011. Scavenger receptor SR-BI in macrophage lipid metabolism. Atherosclerosis 217, 106-112.

Jia, L., Betters, J.L., Yu, L., 2011. Niemann-pick C1-like 1 (NPC1L1) protein in intestinal and hepatic cholesterol transport. Annu Rev Physiol 73, 239-259.

Jones, P.J., Lichtenstein, A.H., Schaefer, E.J., Namchuk, G.L., 1994. Effect of dietary fat selection on plasma cholesterol synthesis in older, moderately hypercholesterolemic humans. Arteriosclerosis, Thrombosis, and Vascular Biology 14, 542-548.

Jones, P.J.H., Pappu, A.S., Hatcher, L., Li, Z.-C., Illingworth, D.R., Connor, W.E., 1996. Dietary Cholesterol Feeding Suppresses Human Cholesterol Synthesis Measured by Deuterium Incorporation and Urinary Mevalonic Acid Levels. Arteriosclerosis, Thrombosis, and Vascular Biology 16, 1222-1228.

Juty, N., Ali, R., Glont, M., Keating, S., Rodriguez, N., Swat, M.J., Wimalaratne, S.M., Hermjakob, H., Le Novere, N., Laibe, C., Chelliah, V., 2015. BioModels: Content, Features, Functionality, and Use. CPT: pharmacometrics \& systems pharmacology 4, e3.

Kersten, S., 2014. Physiological regulation of lipoprotein lipase. Biochim Biophys Acta 1841, 919-933.

Kervizic, G., Corcos, L., 2008. Dynamical modeling of the cholesterol regulatory pathway with Boolean networks. BMC Syst Biol 2, 99.

Le Novère, N., Bornstein, B., Broicher, A., Courtot, M., Donizelli, M., Dharuri, H., Li, L., Sauro, H., Schilstra, M., Shapiro, B., Snoep, J.L., Hucka, M., 2006. BioModels Database: a free, centralized database of curated, published, quantitative kinetic models of biochemical and cellular systems. Nucleic Acids Research 34, D689-D691.

Li, C., Donizelli, M., Rodriguez, N., Dharuri, H., Endler, L., Chelliah, V., Li, L., He, E., Henry, A., Stefan, M., Snoep, J., Hucka, M., Le Novere, N., Laibe, C., 2010. BioModels Database: An enhanced, curated and annotated resource for published quantitative kinetic models. BMC Systems Biology 4, 92.

Lin, D.S., Connor, W.E., 1980. The long term effects of dietary cholesterol upon the plasma lipids, lipoproteins, cholesterol absorption, and the sterol balance in man: the demonstration of feedback inhibition of cholesterol biosynthesis and increased bile acid excretion. Journal of lipid research 21, 1042-1052.

Liscum, L., 2008. Cholesterol biosynthesis, Biochemistry of Lipids, Lipoproteins, and Membranes, 5th ed. Elsevier, pp. 399-422.

Lu, J., Hubner, K., Nanjee, M.N., Brinton, E.A., Mazer, N.A., 2014. An in-silico model of lipoprotein metabolism and kinetics for the evaluation of targets and biomarkers in the reverse cholesterol transport pathway. PLoS Comput Biol 10, e1003509.

Lund-Katz, S., Lyssenko, N.N., Nickel, M., Nguyen, D., Chetty, P.S., Weibel, G., Phillips, M.C., 2013. Mechanisms responsible for the compositional heterogeneity of nascent high density lipoprotein. The Journal of biological chemistry 288, 23150-23160.

Marino, S., Hogue, I.B., Ray, C.J., Kirschner, D.E., 2008. A Methodology For Performing Global Uncertainty And Sensitivity Analysis In Systems Biology. Journal of theoretical biology 254, 178-196.

Mazein, A., Watterson, S., Hsieh, W.Y., Griffiths, W.J., Ghazal, P., 2013. A comprehensive machine-readable view of the mammalian cholesterol biosynthesis pathway. Biochem Pharmacol 86, 56-66.

Mc Auley, M., Jones, J., Wilkinson, D., Kirkwood, T., 2005. Modelling Lipid Metabolism to Improve Healthy Ageing. BMC Bioinformatics 6, P21.

Mc Auley, M.T., Mooney, K.M., 2014. Lipid metabolism and hormonal interactions: impact on cardiovascular disease and healthy aging. Expert Review of Endocrinology \& Metabolism 9, 357-367.

Mc Auley, M.T., Mooney, K.M., 2015. Computationally Modeling Lipid Metabolism and Aging: A Mini-review. Comput Struct Biotechnol J 13, 38-46.

Mc Auley, M.T., Proctor, C.J., Corfe, B.M., Cuskelly, C.J., Mooney, K.M., 2013. Nutrition Research and the Impact of Computational Systems Biology. Journal of Computer Science and Systems Biology 6, 271-285.

Mc Auley, M.T., Wilkinson, D.J., Jones, J.J., Kirkwood, T.B., 2012. A whole-body mathematical model of cholesterol metabolism and its age-associated dysregulation. BMC Syst Biol 6, 130.

McAuley, M.T., Kenny, R.A., Kirkwood, T.B., Wilkinson, D.J., Jones, J.J., Miller, V.M., 2009. A mathematical model of aging-related and cortisol induced hippocampal dysfunction. BMC Neurosci 10, 26.

McNamara, D.J., Kolb, R., Parker, T.S., Batwin, H., Samuel, P., Brown, C.D., Ahrens, E.H., 1987. Heterogeneity of cholesterol homeostasis in man. Response to changes in dietary fat quality and cholesterol quantity. Journal of Clinical Investigation 79, 1729-1739.

Micheloni, A., Orsi, G., De Maria, C., Vozzi, G., 2015. ADMET: ADipocyte METabolism mathematical model. Comput Methods Biomech Biomed Engin 18, 1386-1391.

Millan, J., Pinto, X., Munoz, A., Zuniga, M., Rubies-Prat, J., Pallardo, L.F., Masana, L., Mangas, A., Hernandez-Mijares, A., Gonzalez-Santos, P., Ascaso, J.F., Pedro-Botet, J., 2009. Lipoprotein ratios: Physiological significance and clinical usefulness in cardiovascular prevention. Vasc Health Risk Manag 5, 757-765. 
Millar, J.S., Lichtenstein, A.H., Cuchel, M., Dolnikowski, G.G., Hachey, D.L., Cohn, J.S., Schaefer, E.J., 1995. Impact of age on the metabolism of VLDL, IDL, and LDL apolipoprotein B-100 in men. Journal of lipid research 36, 1155-1167. Mishra, S., Somvanshi, P.R., Venkatesh, K.V., 2014. Control of cholesterol homeostasis by entero-hepatic bile transport - the role of feedback mechanisms. RSC Advances 4, 58964-58975.

Mooney, K.M., Mc Auley, M.T., 2015. Cardiovascular disease and healthy ageing. Journal of Integrative Cardiology 1, 76-78.

Mooney, K.M., Morgan, A.E., Mc Auley, M.T., 2016. Aging and computational systems biology. Wiley Interdisciplinary Reviews: Systems Biology and Medicine 8, 123-139.

Morgan, A.E., Mooney, K.M., Wilkinson, S.J., Pickles, N.A., Mc Auley, M.T., 2016. Cholesterol metabolism: A review of how ageing disrupts the biological mechanisms responsible for its regulation. Ageing Research Reviews 27, 108-124. Moro-Garcia, M.A., Alonso-Arias, R., Baltadjieva, M., Fernandez Benitez, C., Fernandez Barrial, M.A., Diaz Ruisanchez, E., Alonso Santos, R., Alvarez Sanchez, M., Saavedra Mijan, J., Lopez-Larrea, C., 2013. Oral supplementation with Lactobacillus delbrueckii subsp. bulgaricus 8481 enhances systemic immunity in elderly subjects. Age (Dordr) 35, 13111326.

OFNS, 2013. Mortality Assumptions, 2012-based National Population Projections, In: Statistics, O.f.N. (Ed.).

Ohashi, R., Mu, H., Wang, X., Yao, Q., Chen, C., 2005. Reverse cholesterol transport and cholesterol efflux in atherosclerosis. Qjm 98, 845-856.

Olivecrona, G., Beisiegel, U., 1997. Lipid Binding of Apolipoprotein CII Is Required for Stimulation of Lipoprotein Lipase Activity Against Apolipoprotein CII-Deficient Chylomicrons. Arteriosclerosis, Thrombosis, and Vascular Biology 17, 1545-1549.

Parini, P., Angelin, B., Rudling, M., 1999. Cholesterol and Lipoprotein Metabolism in Aging: Reversal of Hypercholesterolemia by Growth Hormone Treatment in Old Rats. Arteriosclerosis, Thrombosis, and Vascular Biology 19, 832-839.

Patsch, J.R., Prasad, S., Gotto, A.M., Jr., Patsch, W., 1987. High density lipoprotein2. Relationship of the plasma levels of this lipoprotein species to its composition, to the magnitude of postprandial lipemia, and to the activities of lipoprotein lipase and hepatic lipase. J Clin Invest 80, 341-347.

Petersen, N.H., Faergeman, N.J., Yu, L., Wustner, D., 2008. Kinetic imaging of NPC1L1 and sterol trafficking between plasma membrane and recycling endosomes in hepatoma cells. Journal of lipid research 49, 2023-2037.

Prince, M.J., Wu, F., Guo, Y., Gutierrez Robledo, L.M., O'Donnell, M., Sullivan, R., Yusuf, S., 2015. The burden of disease in older people and implications for health policy and practice. The Lancet 385, 549-562.

Quintao, E., Grundy, S.M., Ahrens, E.H., Jr., 1971. Effects of dietary cholesterol on the regulation of total body cholesterol in man. Journal of lipid research 12, 233-247.

Rohn, H., Junker, A., Hartmann, A., Grafahrend-Belau, E., Treutler, H., Klapperstuck, M., Czauderna, T., Klukas, C., Schreiber, F., 2012. VANTED v2: a framework for systems biology applications. BMC Syst Biol 6, 139.

Scheibner, J., Fuchs, M., Hormann, E., Tauber, G., Stange, E.F., 1994. Biliary cholesterol secretion and bile acid formation in the hamster: the role of newly synthesized cholesterol. Journal of lipid research 35, 690-697.

Shorten, P.R., Upreti, G.C., 2005. A mathematical model of fatty acid metabolism and VLDL assembly in human liver. Biochim Biophys Acta 1736, 94-108.

Sips, F.L., Tiemann, C.A., Oosterveer, M.H., Groen, A.K., Hilbers, P.A., van Riel, N.A., 2014. A computational model for the analysis of lipoprotein distributions in the mouse: translating FPLC profiles to lipoprotein metabolism. PLoS Comput Biol 10, e1003579.

Sorci-Thomas, M., Babiak, J., Rudel, L.L., 1990. Lecithin-cholesterol acyltransferase (LCAT) catalyzes transacylation of intact cholesteryl esters. Evidence for the partial reversal of the forward LCAT reaction. The Journal of biological chemistry 265, 2665-2670.

Spady, D.K., Cuthbert, J.A., 1992. Regulation of hepatic sterol metabolism in the rat. Parallel regulation of activity and mRNA for 7 alpha-hydroxylase but not 3-hydroxy-3-methylglutaryl-coenzyme A reductase or low density lipoprotein receptor. The Journal of biological chemistry 267, 5584-5591.

Tanaka, H., Doesburg, K., Iwasaki, T., Mierau, I., 1999. Screening of lactic acid bacteria for bile salt hydrolase activity. J Dairy Sci 82, 2530-2535.

Tannock, G.W., Dashkevicz, M.P., Feighner, S.D., 1989. Lactobacilli and bile salt hydrolase in the murine intestinal tract. Appl Environ Microbiol 55, 1848-1851

Trautwein, E.A., Siddiqui, A., Hayes, K.C., 1999. Characterization of the bile acid profile in developing male and female hamsters in response to dietary cholesterol challenge. Comp Biochem Physiol A Mol Integr Physiol 124, 93-103.

Tuohy, K.M., Probert, H.M., Smejkal, C.W., Gibson, G.R., 2003. Using probiotics and prebiotics to improve gut health. Drug Discovery Today 8, 692-700.

Uchida, K., Satoh, T., Chikai, T., Takase, H., Nomura, Y., Nakao, H., Takeuchi, N., 1996. Influence of cholesterol feeding on bile acid metabolism in young and aged germ-free rats. Jpn J Pharmacol 71, 113-118.

van de Pas, N.C., Woutersen, R.A., van Ommen, B., Rietjens, I.M., de Graaf, A.A., 2012. A physiologically based in silico kinetic model predicting plasma cholesterol concentrations in humans. Journal of lipid research 53, 2734-2746.

Watterson, S., Guerriero, M.L., Blanc, M., Mazein, A., Loewe, L., Robertson, K.A., Gibbs, H., Shui, G., Wenk, M.R. Hillston, J., Ghazal, P., 2013. A model of flux regulation in the cholesterol biosynthesis pathway: Immune mediated graduated flux reduction versus statin-like led stepped flux reduction. Biochimie 95, 613-621.

WHO, 2014. Aging and Life Course: Facts about Aging. WHO.

Woollett, L.A., Spady, D.K., Dietschy, J.M., 1992. Saturated and unsaturated fatty acids independently regulate low density lipoprotein receptor activity and production rate. Journal of lipid research 33, 77-88.

Yang, W., Xiao, J., Yang, Z., Ji, L., Jia, W., Weng, J., Lu, J., Shan, Z., Liu, J., Tian, H., Ji, Q., Zhu, D., Ge, J., Lin, L., Chen, L., Guo, X., Zhao, Z., Li, Q., Zhou, Z., Shan, G., He, J., 2012. Serum Lipids and Lipoproteins in Chinese Men and Women. Circulation 125, 2212-2221.

Zhang, M., Charles, R., Tong, H., Zhang, L., Patel, M., Wang, F., Rames, M.J., Ren, A., Rye, K.A., Qiu, X., Johns, D.G., Charles, M.A., Ren, G., 2015. HDL surface lipids mediate CETP binding as revealed by electron microscopy and molecular dynamics simulation. Sci Rep 5, 8741.

Zhong, S., Sharp, D.S., Grove, J.S., Bruce, C., Yano, K., Curb, J.D., Tall, A.R., 1996. Increased coronary heart disease in Japanese-American men with mutation in the cholesteryl ester transfer protein gene despite increased HDL levels. J Clin Invest 97, 2917-2923. 
